\title{
RENATO ZANIN
}

Eficiência da produção de embriões in vitro através de aspiração folicular transvaginal em bovinos das raças Girolando, Brangus e Nelore

Dissertação apresentada ao Programa de PósGraduação em Anatomia dos Animais Domésticos e Silvestres da Faculdade de Medicina Veterinária e Zootecnia da Universidade de São Paulo para a obtenção do título de Mestre em Ciências

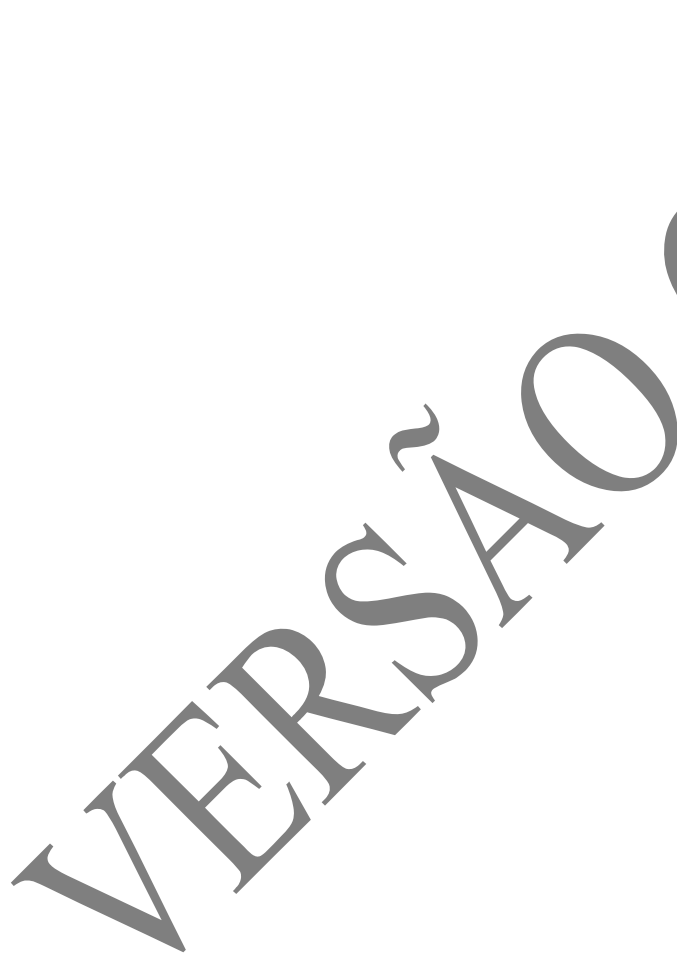

Área de Concentração:

Anatomia dos Animais Domésticos e Silvestres

Orientador:

Prof. Dr. Luciano Andrade Silva

São Paulo

2013

Obs: A versão original se encontra disponível na Biblioteca da FMVZ/USP 
Autorizo a reprodução parcial ou total desta obra, para fins acadêmicos, desde que citada a fonte.

DADOS INTERNACIONAIS DE CATALOGAÇÃO-NA-PUBLICAÇÃO

(Biblioteca Virginie Buff D’Ápice da Faculdade de Medicina Veterinária e Zootecnia da Universidade de São Paulo)

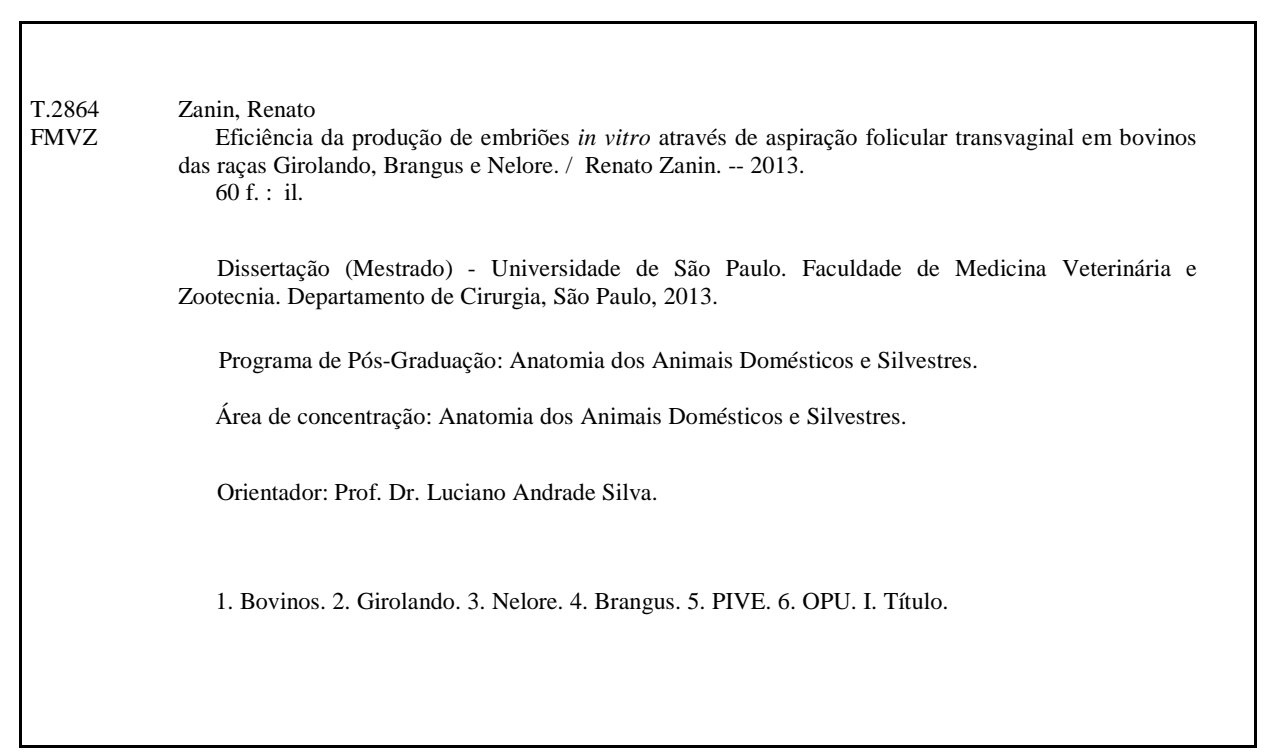




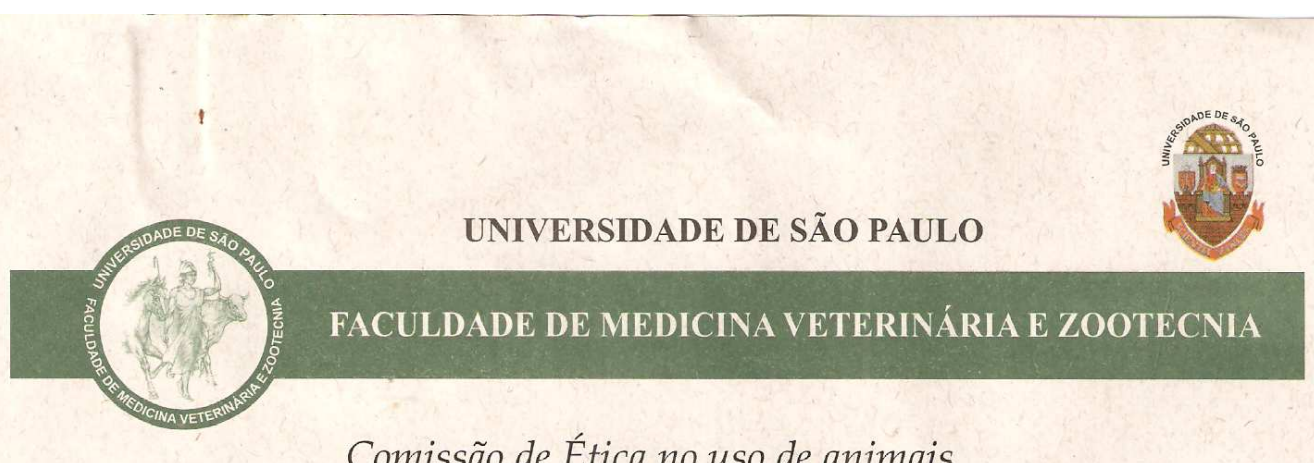

Comissão de Ética no uso de animais

\section{CERTIFICADO}

Certificamos que o Projeto intitulado ."Eficiência da produção de embriões in vitro através de aspiração folicular transvaginal em bovinos das raças Girolando, Brangus e Nelore", protocolado sob o no 3031/2013, utilizando 194 (cento e noventa e quatro) bovinos, sob a responsabilidade do Prof. Dr. Luciano Andrade Silva, está de acordo com os princípios éticos de experimentação animal da "Comissão de Ética no uso de animais" da Faculdade de Medicina Veterinária e Zootecnia da Universidade de São Paulo e foi aprovado em reunião de, 15/5/2013.

We certify that the Research "Efficiency of in vitro production of embryos by transvaginal follicle aspiration in Girolando, Brangus and Nellore cettle breeds", protocol number 3031/2013, utilizing 194 (one hundred, ninety four) bovine, under the responsibility Prof. Dr. Luciano Andrade Silva, agree with Ethical Principles in Animal Research adopted by "Ethic Committee in the use of animals" of the School of Veterinary Medicine and Animal Science of University of São Paulo and was approved in the meeting of day 5/15/2013.

São Paulo, 20 de maio de 2013.

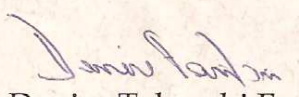

Denise Tabacchi Fantoni

Presidente 


\section{FOLHA DE AVALIAÇÃO}

Nome: ZANIN, Renato.

Título: Eficiência da produção de embriões in vitro através de aspiração folicular transvaginal em bovinos das raças Girolando, Brangus e Nelore

Data:

Dissertação apresentada ao Programa de Pós-Graduação em Anatomia dos Animais Domésticos e Silvestres da Faculdade de Medicina Veterinária e Zootecnia da Universidade de São Paulo para a obtenção do título de Mestre em Ciências

\section{Banca Examinadora}

Prof. Dr.

Instituição: Julgamento

Prof. Dr.

Instituição: Julgamento

Prof. Dr.

Instituição: Julgamento 
DEDICO

Á minha família, em especial meus pais Nelson e Ilana e à minha esposa Roberta. 


\section{AGRADECIMENTOS}

Primeiramente agradeço a Deus, pois acredito que sem ele nada é possível.

Agradeço a todos meus familiares, em especial aos meus pais Nelson e Ilana por me apoiarem e estarem sempre ao meu lado como pilares essenciais para construção de minha vida pessoal e profissional. Ao meu irmão Rafael, sempre companheiro e amigo, um exemplo de pessoa.

Agradeço a minha esposa Roberta pelo apoio, companheirismo, compreensão, dedicação e paciência em seus ensinamentos, sempre estando ao meu lado nas horas boas e ruins me dando força para vencer minhas dificuldades, se tornando uma pessoa essencial para minha vida. Obrigado por estar ao meu lado.

Durante minha formação profissional e acadêmica nesta etapa, tive a honra de conhecer pessoas que fizeram e fazem parte de minha história como Prof. Dr. Otávio M. Ohashi, Prof. Dr. Luiz F. C. Cunha Filho, Samuel Guemra, Profa. Dra. Maria Angélica Miglino, Prof. Dr. Paulo R. Adona, Prof. Dr. Paulo Monzani, em especial a empresa Agrop. Laffranchi e ao Prof. Marco A. Laffranchi por terem me dado a oportunidade ingressar e concluir este mestrado, com certeza nunca me esquecerei destas pessoas.

Nada disso seria possível sem a orientação e os ensinamentos do Prof. Dr. Luciano Andrade Silva. Agradeço imensamente por ter aceitado o convite de me orientar, e pelo voto de confiança em mim depositado, realmente me sinto muito honrado em ser seu orientado.

Não posso me esquecer de algumas pessoas, amigos e familiares, os quais sempre me apoiaram e mesmo distantes, estão presentes em minha vida. Minhas avós, tios, primos, cunhadas, sogra e sogro, que sempre estarão acima de todas as conquistas. Por fim devo um especial agradecimento a todos os amigos e amigas que estiveram comigo durante o mestrado, na minha vida particular e no trabalho. Evito citar nomes, pois são inúmeros para poucas páginas. Apesar de alguns estarem distantes no momento, sei que posso contar com todos.

Agradeço a todos os professores e ao programa de pós-graduação de Anatomia dos Animais Domésticos e Silvestres da Faculdade de Medicina Veterinária e Zootecnia da Universidade de São Paulo, pelo conhecimento adquirido durante este período de mestrado.

Muito obrigado!!! 


\section{RESUMO}

ZANIN, R. Eficiência da produção de embriões in vitro através de aspiração folicular transvaginal em bovinos das raças Girolando, Brangus e Nelore. [Efficiency of in vitro embryos production through transvaginal follicular aspiration in Girolando, Brangus , and Nelore cattle breeds]. 2013. 60 f. Dissertação (Mestrado em Ciência) - Faculdade de Medicina Veterinária e Zootecnia, Universidade de São Paulo, São Paulo, 2013.

O presente estudo foi realizado no Laboratório de Reprodução Animal da Empresa Agropecuária Laffranchi Com. Ind. LTDA, localizada no município de Tamarana - Paraná. O experimento se refere aos resultados obtidos na produção in vitro de embriões através da aspiração folicular transvaginal em bovinos das raças Nelore (CEIP- Certificado Especial de Identificação e Produção), Bos indicus, $\mathrm{n}=22$, Nelore (não CEIP- sem Certificado Especial de identificação e Produção), Bos indicus, $\mathrm{n}=34$, Brangus (5/8 Bos taurus x 3/8 Bos indicus, $\mathrm{n}=64)$ e Girolando (5/8 Bos taurus $x$ 3/8 Bos indicus, $\mathrm{n}=52)$ totalizando 172 animais, no período de 01 janeiro de 2010 a 31 de dezembro de 2012. Todos os animais foram submetidos à OPU (Ovum Pick Up) totalizando 397 procedimentos entre as doadoras, sendo 104 OPUs em Nelore (não CEIP), 52 OPUs em Nelore (CEIP), 133 OPUs em Brangus e 108 OPUs em Girolando. Com estes procedimentos foram aspirados 7335 oócitos, destes 3597 foram considerados viáveis (49\%), produzindo 969 embriões (26.93\%), destes foram transferidos 922 embriões em receptoras previamente selecionadas, resultando em 266 prenhes (taxa de prenhes $28.85 \%$ ). Após a obtenção dos oócitos estes eram enviados para o laboratório acima citado para maturação, fecundação e cultivo in vitro, em um período de oito dias. Os embriões produzidos eram transferidos para receptoras de embrião previamente selecionadas e submetidas ao protocolo de TETF (transferência de embrião em tempo fixo), sendo o diagnóstico de gestação realizado aos 30 dias com auxílio de ultrassonografia transretal. $\mathrm{Na}$ raça Brangus recuperou-se um total de 2139 oócitos sendo 967 viáveis (45,2\%), destes foram obtidos 272 embriões os quais foram transferidos 241 embriões resultando em 81 prenhezes (33,3\%). Na raça Girolando, foram recuperados 1806 oócitos, destes 972 foram considerados viáveis (53.8\%) e resultaram na produção de 251 embriões (25.8\%), os quais foram transferidos 245, obtendo-se 61 prenhezes (24.9\%). Com relação às doadoras da raça Nelore (CEIP), recuperou-se 1850 oócitos, destes 842 foram considerados viáveis (45.5\%), resultando em 214 embriões (25.4\%), obtendo-se 61 prenhezes (28.5\%). Na raça Nelore (não CEIP) recuperou-se 1540 oócitos sendo 816 considerados viáveis (53.0\%), os quais 
resultaram na produção de 232 embriões (28.4\%), sendo transferidos 222 dos quais se obteve 63 prenhezes (28.4\%). De acordo com a análise estatística observou-se que a raça Nelore (CEIP) teve resultados superiores de $(\mathrm{P}<0.0001)$ em relação à média total de oócitos por OPU, total de oócitos viáveis por sessão de OPU $(\mathrm{P}<0.0001)$, produção de embriões $(\mathrm{P}<$ 0.0001) e prenhes por OPU $(\mathrm{P}<0,0115)$. O presente trabalho forneceu dados inéditos de PIVE (produção in vitro de embriões) para discussão nas raças sintéticas Brangus e Girolando (Bos tauros x Bos indicus), em larga escala, porém, o experimento também destaca a necessidade de mais estudos relacionados à PIVE nessas raças. Quanto ao comparativo entre as raças, observou que a quantidade total de oócitos não variou de acordo com as raças Brangus, Girolando e Nelore (não CEIP), no entanto podemos notar uma grande variação individual de animais da mesma raça, Nelore (CEIP) e Nelore (não CEIP), onde se obteve nas fêmeas da raça Nelore (CEIP, selecionadas) uma maior produção total de oócitos, oócitos viáveis e embriões por sessão de aspiração.

Palavras-chave: Bovinos. Girolando. Nelore. Brangus. PIVE. OPU. 


\begin{abstract}
ZANIN, R. Efficiency of in vitro embryos production through transvaginal follicular aspiration in Girolando, Brangus, and Nelore cattle breeds. [Eficiência da produção de embriões in vitro através de aspiração folicular transvaginal em bovinos das raças Girolando, Brangus e Nelore]. 2013. 60 f. Dissertação (Mestrado em Ciência) - Faculdade de Medicina Veterinária e Zootecnia, Universidade de São Paulo, São Paulo, 2013.
\end{abstract}

This study was developed at the Laboratory of Animal Reproduction from the "Empresa Agropecuária Laffranchi Com. Ind. LTDA”, town of Tamarana, Paraná State, Brazil. Results from in vitro production of cattle embryos through follicular aspiration in the breeds Nelore (CEIP- Special Certificate of Identification and Production), Bos indicus, $\mathrm{n}=22$, Nelore (no CEIP- no Special Certificate of Identification and Production), Bos indicus, $\mathrm{n}=34$, Brangus (5/8 Bos taurus $x 3 / 8$ Bos indicus, $\mathrm{n}=64)$ e Girolando (5/8 Bos taurus $x 3 / 8$ Bos indicus, $\mathrm{n}=$ 52) from January $1^{\text {st }}$ of 2010 to December 31th of 2012 were used totalizing 397 oocyte donors OPU (Ovum Pick Up). From those, 104 OPU were realized in Nelore (no CEIP), 52 OPUs in Nelore (CEIP), 133 OPUs in Brangus, and 108 OPUs in Girolando. The total of recovered oocytes was 7335 . Then, the oocytes were sent to the Laboratory for in vitro maturation, fertilization and culture during a period of eight days. The number of viable oocytes was 3597 (49\%) and 969 embryos were in vitro produced (26.9\%). A total of 922 were transferred to recipients previously selected and submitted to estrous synchronization using the farm routine FTET (fixed-time embryo transfer) protocol. The pregnancy rate was $28.9 \%$ (266 pregnancies). Pregnancy diagnosis was done at the embryo age of 30 days using B-mode transrectal ultrasonography. From Brangus cows, a total of 2139 oocytes were recovered and 967 were classified as viable (45.2\%), 272 embryos were produced and 241 were transferred resulting in 81 pregnancies (33.3\%). From Girolando cows, 1806 oocytes were recovered and 972 classified as viable (53.8\%). A total of 251 embryos (25.8\%) were produced, 245 transferred and the pregnancy rate was $24.9 \%$ (61 pregnancies).From the Nelore CEIP cows, a total of 1850 oocytes were recovered and 842 were classified as viable (45.5\%), 214 embryos were produced and 214 were transferred resulting in 61 pregnancies (28.5\%).From Nelore cows, 1540 oocytes were recovered and 816 classified as viable $(53.0 \%)$. A total of 232 embryos $(28.4 \%)$ were produced, 222 transferred and the pregnancy rate was $28.4 \%$ (63 pregnancies).The Nelore CEIP presented superior results for the number of oocytes recovered per OPU $(P<0.0001)$, for the total of viable oocytes per OPU $(P<0.0001)$, embryos produced $(P<0.0001)$, and total of pregnancies per OPU procedures $(P<0.0115)$. This work presents for the first time data from IVPE from Brangus and 
Girolando breeds (Bos taurosx Bos indicus). When the four studied breeds were compared, the results showed a considerable variation between animals in the same breed. Also, it was observed, in the same breed Nelore, a superiority of the Nelore CEIP for oocyte recovery rate, viable oocytes e total of embryos produced by OPU procedure.

Key words: Cow. Girolando. Nelore. Brangus. IVPE. OPU. 


\section{LISTA DE FIGURAS}

Figura 1 - Média da produção total de oócitos por sessão de OPU nas diversas raças............

Figura 2 - Comparação de óocitos viáveis x não viáveis por sessão de OPU

Figura 3 - Porcentagem de oócitos viáveis e não viáveis entre as diferentes raças.

Figura 4 - Produção de embriões a partir do número de oócitos por sessão de OPU.

Figura 5 - Porcentagem de embriões produzidos de acordo com o número total de oócitos viáveis nas diferentes raças analisadas

Figura 6 - Média de embriões transferidos por OPU com relação às prenhezes........................

Figura 7- Taxa de prenhez comparada entre as diferentes raças. 


\section{LISTA DE TABELA}

Tabela 1- Resultados gerais e individuais por raça nas aspirações das raças Brangus, Girolando, Nelore CEIP e Nelore. 


\section{SUMÁRIO}

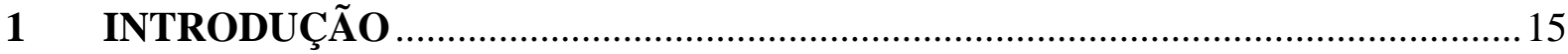

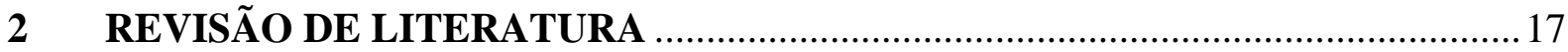



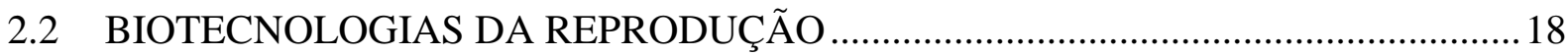



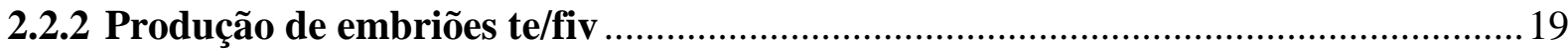

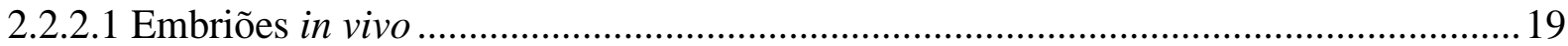

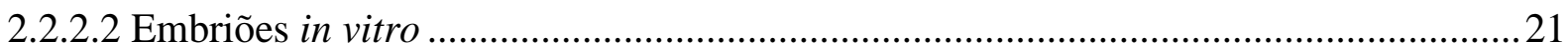

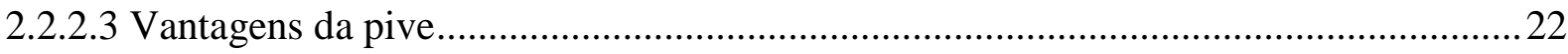



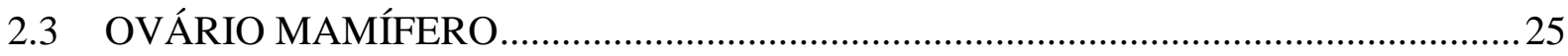

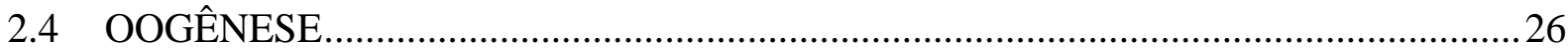

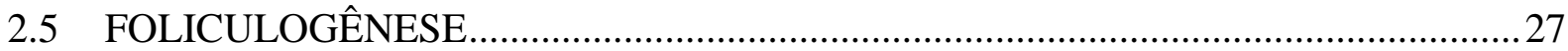

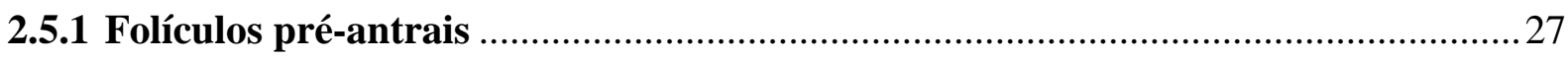



2.5.3 Ativação e crescimento do folículos pré-antrais ......................................................29

2.6 POPULAÇÃO FOLICULAR EM OVÁRIOS MAMÍFEROS ......................................... 30

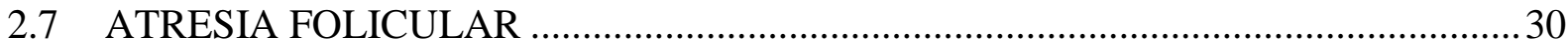

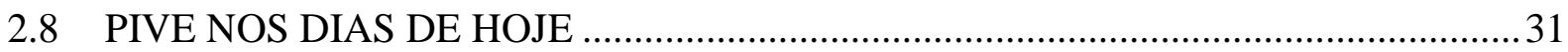

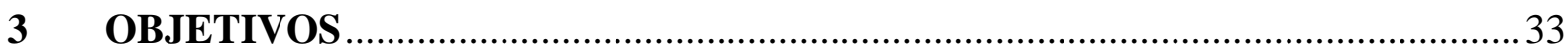

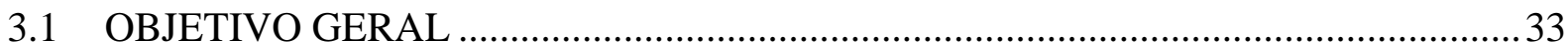

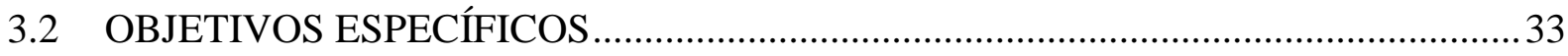

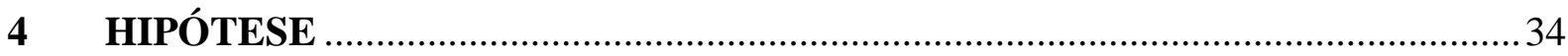



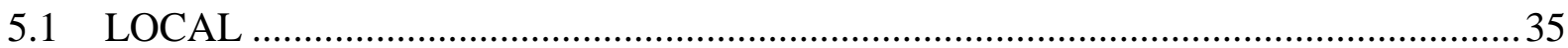

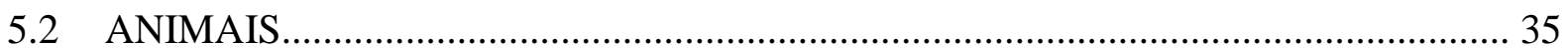

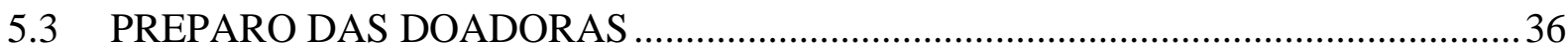



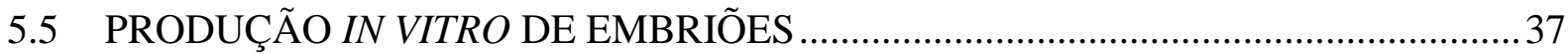

5.6 PROTOCOLO DE TRASNFERÊNCIA DE EMBRIÕES .............................................38

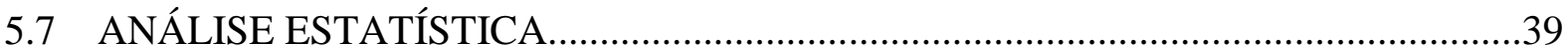




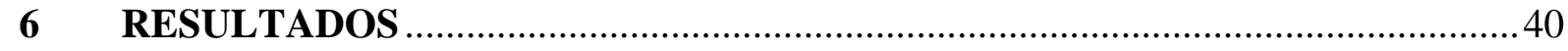

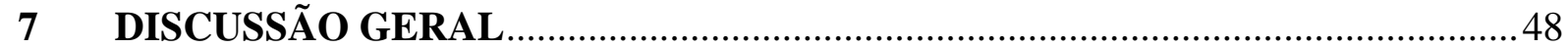

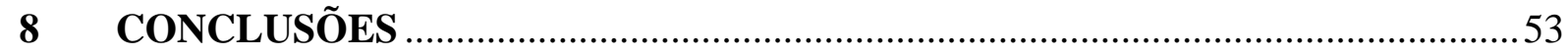

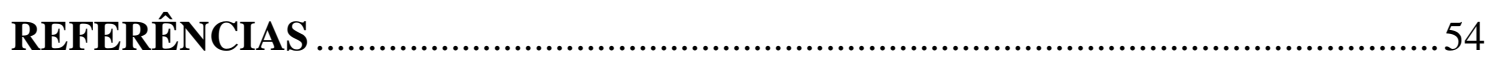




\section{INTRODUÇÃO}

A pecuária nacional tem se destacado no mercado mundial. O Brasil é o maior exportador de carne bovina e o segundo maior rebanho efetivo de bovinos do mundo. Com este potencial junto ao melhoramento genético, é possível identificar através de programas de melhoramento os melhores reprodutores e matrizes para produção de carne e leite. Com isso se torna necessário a utilização de ferramentas eficientes para a multiplicação destes indivíduos melhoradores. Os estudos das biotecnologias da reprodução entre raças produtoras de carne e leite se tornam cada vez mais necessário para acelerar este melhoramento genético.

O desenvolvimento de novas biotecnologias na reprodução animal tem provocado um aumento significativo na produção animal. Na espécie bovina, se iniciou com a inseminação artificial (IA), a qual se pode geralmente explorar apenas o potencial genético do reprodutor em fêmeas muitas vezes geneticamente inferiores, obtendo-se apenas um bezerro por vaca/ano. Com o surgimento da transferência de embriões (TE) pode-se utilizar touros e vacas superiores zootecnicamente aumentando as possibilidades de se obter uma progênie mais produtiva, podendo uma única doadora aumentar sua produção em até 10 vezes. Com o advento da aspiração folicular (OPU) seguida de fecundação in vitro de embriões (FIV) esta produção pode ser ainda maior podendo chegar a até 50 bezerros por vaca/ano, permitindo um melhor aproveitamento dos gametas femininos e a utilização de touros com altos índices zootécnicos e geneticamente superiores. Além disso, a OPU/FIV facilita a utilização de sêmen sexado que tem sido aplicado com bastante sucesso para produção de fêmeas na bovinocultura leiteira e para a produção de machos em animais de corte. Sendo assim, a produção in vitro de embriões (PIV) tem sido explorada em escala comercial por várias empresas particulares no intuito de intensificar a produtividade e acelerar o melhoramento genético em rebanhos bovinos.

O Brasil por ser um país tropical, necessita de bovinos que se adaptem às variedades climáticas mantendo uma boa produção de leite e carne. Devido a isso, surgiram raças sintéticas como o Girolando (5/8 Holandês x 3/8 Gir) para produção de leite e a raça Brangus (5/8 Angus x 3/8 Zebu) para produção de carne, e ainda pouco se conhece em termos de resultados de PIV dessas duas raças. Sendo assim, o presente Trabalho comparou a PIVE de duas raças sintéticas dos trópicos (Girolando e Brangus) com a maior raça pura em número de matrizes no Brasil (Nelore). Comparando fêmeas Nelore (não CEIP), com Nelore (CEIP), este 
certificado é emitido pelo ministério da agricultura para animais que participam de programas rigorosos de melhoramento genético, onde apenas animais melhoradores em termos de fertilidade e produção conquistam este certificado (CEIP).

O experimento teve como objetivo principal a avaliação da produção total de oócitos, produção total e porcentagem de oócitos viáveis, embriões e prenhes por vaca e procedimento de OPU, e comparara-las quanto a produtividade entre as raças avaliadas.

Os dados resultantes deste trabalho forneceram dados sobre a produção in vitro de embriões em raças sintéticas, sendo encontrada maior produção in vitro embriões nos animais da raça Nelore, visto que estes animais apresentam um número maior de ondas foliculares por ciclo ovulatório (três ondas foliculares) ocasionando o recrutamento de mais folículos por ciclo. Os animais da raça Girolando e Brangus por se tratarem de animais sintéticos com maior grau de sangue taurino (5/8 Bos taurus x 3/8 Bos indicus) apresentam um número menor de ondas foliculares por ciclo ovulatório (duas ondas foliculares) ocasionando um menor recrutamento folicular por ciclo estral.

Até a presente data não foram encontrados trabalhos em literatura detalhando a PIVE nas raças Brangus e Nelore (CEIP), portanto este trabalho serve como base de dados na produção in vitro de embriões nestas raças. 


\section{REVISÃO DE LITERATURA}

\subsection{PECUÁRIA NACIONAL}

A bovinocultura no Brasil é um dos principais destaques do agronegócio brasileiro no mercado interno e externo. O Brasil ocupa a posição de segundo maior rebanho efetivo do mundo com cerca de 200 milhões de cabeças de bovinos, e desde 2004 ocupa a primeira colocação nas exportações, totalizando um quinto da carne comercializada no mundo. Segundo o Ministério da agricultura, até 2020, a expectativa da produção de carne no Brasil pode suprir 44,5\% do mercado mundial (MAPA, [200-]).

Segundo previsões do MAPA (2012) a estimativa de crescimento da produção leite dos anos de 2012 até 2022 aumentará de 32.539 milhões/litros/ano para 39.250 milhões/litros/ano, enquanto é previsto um aumento de 33.413 milhões/litros em 2012 para 40.208 milhões/litros em 2022, ou seja, a produção em dez anos será menor que o consumo.

Atualmente, os produtores dispõem de diversos programas de melhoramento genético muito bem elaborados que permitem identificar em uma população os animais destaques com maior probabilidade de acerto comparado a uma seleção empírica. E, tal ferramenta, proporciona ganhos genéticos de forma mais acelerada (PARCKERT; GALLO, 2011).

Amer et al. (2001) relata que é importante se ter uma definição dos objetivos econômicos para o desenvolvimento de estratégias do melhoramento genético e identificação de critérios de seleção para se ter um melhor contribuição na predição das características que afetam a lucratividade dos rebanhos comerciais.

Todos os programas de melhoramento genético que são utilizados no Brasil possuem um índice, normalmente baseado em agregados genotípicos os quais podem levar em consideração características de crescimento e sexuais e alguns incorporam características de conformação (LÔBO et al., 2000).

No Brasil, têm-se disponíveis vários programas de melhoramento genético como o Programa de Seleção da Estação Experimental de Zootecnia de Sertãozinho - Instituto de Zootecnia, Programa de Melhoramento Genético de Zebuínos - PMGZ - ABCZ, Progenel, 
Programa de Melhoramento Genético da Raça Nelore - PMGRN, Programa Qualitas, Sumário Aliança Nelore, Sumário Paint Consolidado, Programa CFM e a Conexão Delta G (PARCKERT; GALLO, 2011).

Todos os animais que são melhorados através de programas de melhoramento genético, indicados pelo programa e avaliados pelos técnicos credenciados, recebem o CEIP (Certificado Especial de Identificação e Produção), o qual garante o desempenho do animal informando os índices das características produtivas avaliadas. O MAPA (Ministério da Agricultura) reconhece o CEIP e dá equivalência ao registro, mantendo seus benefícios. Os melhores animais de cada safra ainda podem ser candidatos ao teste de progênie para comprovação da sua produção (PARCKERT; GALLO, 2011). Com o surgimento de tecnologias na nutrição e reprodução pode-se intensificar a produção animal tanto para produção de carne e leite.

\subsection{BIOTECNOLOGIAS DA REPRODUÇÃO}

As biotecnologias se iniciaram com a inseminação artificial (IA), em seguida com a coleta de embriões in vivo e por ultimo a produção in vitro de embriões.

\subsubsection{Inseminação Artificial}

A inseminação artificial foi introduzida em 1950 se tornando mais popular na década de 60 e 70. A primeira IA bem sucedida em mamíferos foi obtida em cães da raça Poodle no ano de 1779 por Lazzaro Spallanzani. Em 1951, Stewart obteve o nascimento do primeiro bezerro proveniente de inseminação artificial com sêmen congelado (AX et al., 2004; VAN WAG TENDONK-DE LEEUW, 2006; REICHENBACH et al., 2008).

As vantagens da IA se iniciaram com o surgimento de centrais de touros e sistemas baseados em avaliação genética de bovinos tornando a possibilidade de gerar múltiplos produtos de um touro em um curto espaço de tempo, o que permitiu avaliar estes através de 
desempenho de seus produtos. Com isso, os touros geneticamente superiores foram identificados e selecionados e a IA contribuiu mais rapidamente com a disseminação de genes superiores destes animais nos rebanhos nacionais e internacionais. Adicionalmente, a IA e uma ferramenta importante contra a transmissão de doenças venéreas entre animais (AX et al., 2004; VAN WAG TENDONK-DE LEEUW, 2006; REICHENBACH et al., 2008).

\subsubsection{Produção de embriões TE/FIV}

O número total de bovinos oriundos de embriões in vitro e in vivo no mundo cresceu consideravelmente, sendo em 2009 de 843.862 para 930.993 em 2010 (STROUD \& CALLESEN, 2012).

\subsubsection{Embriões in vivo (TE)}

O nascimento do primeiro bezerro de TE foi em 1951 pelos pesquisadores Willett e colaboradores. De acordo com Jainudeen et al. (2004) em 1973 nasceu o primeiro bezerro oriundo de embrião congelado produzido pelos pesquisadores Wilmut e Rowson. Segundo Reichenbach et al. (2008) a TE iniciou comercialmente nos Estado Unidos em 1970 e a primeira tentativa no Brasil foi em 1977.

No inicio da década de 70, a superovulação e a transferência de embriões (TE) foi desenvolvida envolvendo a administração de hormônios em vacas doadoras para induzir mais que uma ovulação natural, ou seja, múltiplas ovulações. Os oócitos ovulados são fertilizados depois de uma IA convencional e embriões são produzidos e os mesmos migram do oviduto ao útero. No dia 7 após a IA, os embriões estão no corno uterino e podem ser lavados e recuperados do útero (VAN WAG TENDONK-DE LEEUW, 2006). Segundo Jainudeen et al. (2004) esta técnica permite que fêmeas superiores geneticamente sejam superovuladas com hormônios gonadotróficos e seus oócitos são fecundados in vivo, os embriões resultantes são transferidos em receptoras de embrião com potencial genético inferior. Inicialmente todos os 
embriões até 1970 eram transferidos via técnica cirúrgica para receptoras. Posteriormente, técnicas não cirúrgicas, como a via transcervical, foram desenvolvidas para a coleta e transferência de embriões, sendo a mesma utilizada até os dias de hoje (SENEDA et al., 2002; VAN WAG TENDONK-DE LEEUW, 2006; REICHENBACH et al., 2008).

As vantagens da TE com relação a IA, é a maior intensidade de seleção sobre as fêmeas e aumento da acurácia de seleção (VAN WAG TENDONK-DE LEEUW, 2006). Com a TE pode-se aumentar em até dez vezes o número de produtos de uma vaca por ano, já com a IA se obtém apenas um bezerro por vaca por ano (BASSO et al., 2010). O amento da taxa de reprodução de fêmeas com alto valor genético, também exerce grande importância para preservação da diversidade genética através da criopreservação de embriões, e possibilita o transporte de embriões congelados entre rebanhos (REICHENBACH et al., 2008).

As restrições do uso da TE segundo Bols et al. (1997) estão nas diferentes respostas aos estímulos gonadotróficos nos diferentes animais e também pela presença de estruturas não fecundadas nas colheitas. Reichenbach et al. (2008) descreveram uma alta variabilidade da terapia hormonal decorrente de fatores ligados ao meio ambiente como nutrição, estabulação e temperatura ambiental, entre outros, e fatores ligados às doadoras como idade, raça, genética, sensibilidade ao estresse, produção de leite e outros fatores ligados à produção e, conservação e aplicação dos hormônios. Estes autores descrevem também que mesmo as doadoras estando em condições ideais, a ausência da resposta ao tratamento superovulatório pode ocorrer em $20 \%$ destes animais, e que apenas de 30 a $35 \%$ das vacas se consegue obter uma média de seis embriões viáveis por colheita. Bak et al. (1989) observaram a presença de cistos ovarianos, endometrites e lesões iatrogênicas em doadoras submetidas aos procedimentos de colheita de embriões.

Muitos fatores são críticos para o sucesso na transferência de embriões como a experiência do transferidor, técnica, raça e idade das doadoras e receptoras, e tempo e intervalo entre o estro da doadora e a recuperação do embrião, sincronia do estro entre a doadora e receptora, estágio embrionário, mês e estação da transferência (HANEKAMP, 1999; PEIXOTO et al., 2007).

De acordo com Stroud e Callesen (2012), o número de coletas de embriões bovinos sobem menos de $1 \%$ de 2009 a 2010. Apesar disso, o número de embriões transferidos subiu mais de $10 \%$, sendo que a transferência de embriões congelados oriundos da superovulação de doadoras corresponde à maior parte desta diferença. Com exceção da África do Sul, é 
notável a distribuição uniforme entre todos os continentes referente ao número de embriões transferidos.

A América do Sul apresentou um crescimento modesto de 2009 a 2010 no número de lavados (colheitas de embriões) sendo 11.634 e 12.263 respectivamente, porém, apresentou um aumento expressivo no número de embriões produzidos in vivo transferidos em receptoras (de 59.032 em 2009 para 71.558 em 2010), mostrando que a América do Sul transfere mais de $12 \%$ dos embriões produzidos in vivo do mundo. O Brasil ocupa o primeiro lugar em produção e transferência de embriões in vivo da América do Sul (38.975), em segundo está a Argentina (24.263) e seguido pelo Uruguai (3.402) (STROUD; CALLESEN, 2012).

A maioria das superovulações e transferência de embriões no Brasil utilizam os embriões de animais Zebu (Bos indicus) e receptoras oriundos do cruzamento de Bos indicus x Bos taurus devido sua maior disponibilidade e resistência ao estresse ambiental dos trópicos (PEIXOTO et al., 2007).

Globalmente, um número superior de embriões congelados derivados in vivo foi transferido de 2009 para 2010 comparado aos embriões frescos (263.036 e 327.525 respectivamente) (STROUD; CALLESEN, 2012).

Com relação ao número de embriões derivados in vivo e transferidos no mundo, o Brasil ocupou a terceira posição em 2010 (38.975), atrás apenas do Japão (77.569) e Austrália (59.600) (STROUD; CALLESEN, 2012).

\subsubsection{Embriões in vitro (FIV)}

Em 1978, aconteceu o nascimento do primeiro embrião humano de FIV realizado por Louise Brown e a partir daí iniciou-se o desenvolvimento de técnica para uso em bovinos (VAN WAG TENDONK-DE LEEUW, 2006; GONÇALVES et al., 2008). Oócitos maduros foram cirurgicamente recuperados de ovários e ovidutos de vacas estimuladas através de hormonioterapia e subsequentemente foram fertilizados cultivados in vitro e depois transferidos resultando em 1981, no nascimento de Virgilio, o primeiro bezerro de FIV (BRACKETT et al., 1982). 
Pieterse et al. (1988) alteraram a técnica descrita para humanos e descreveram a aspiração folicular via transvaginal através da ultrassonografia, que tornou viável o aproveitamento de oócitos bovinos, sem as limitações dos procedimentos existentes até então.

A OPU no inicio apresentou-se como uma alternativa de recuperação de oócitos para fêmeas com limitações reprodutivas, e posteriormente utilizadas de forma mais ampla e produtiva em fêmeas saudáveis e animais pré púberes, produzindo quatro vezes mais embriões em relação a TE (KRUIP et al., 1994). Após avaliações, a técnica mostrou-se simples e inócua, viabilizando a recuperação, maturação e fecundação de oócitos imaturos, podendo ser repetida várias vezes em um mesmo animal (BOLS et al., 1991; PIETERSE et al., 1991).

Atualmente, a tecnologia de OPU e PIV consiste em aspirar oócitos de vacas geneticamente superiores pré-selecionadas através da ultrassonografia transvaginal seguida da maturação in vitro, fertilização e cultivo destes embriões os quais se desenvolvem nos estágios de mórula ou blastocisto e podem ser transferidos de forma não-cirúrgica para receptoras ou submetidos ao congelamento (VAN WAG TENDONK-DE LEEUW, 2006).

\subsubsection{Vantagens da PIVE}

De acordo com Gonçalves et al. (2008) esta biotecnica proporciona, acelerar a produção de animais geneticamente superiores e impedir, por meio de aspiração in vivo de folículos guiada por ultrassonografia, o descarte precoce de fêmeas geneticamente privilegiadas portadoras de alterações adquiridas que impeçam a reprodução de ocorrer de forma natural ou até mesmo pela transferência de embriões. A OPU também apresenta como vantagem o curto intervalo de tempo entre os procedimentos (mínimo de 15 dias, sendo provavelmente o que contribui na preferência da mesma comparado à colheita de embriões nas doadoras da raça Nelore (PONTES et al., 2011). A PIVE pode permitir a obtenção de múltiplos embriões/fêmea/ano com um regime de duas punções semanais por doadora, durante vários meses, superando a eficiência da TE convencional a custos inferiores (GONÇALVES et al., 2002; VAN WAG TENDONK-DE LEEUW, 2006). É reconhecido que a OPU, e particularmente a FIV, trouxe a base para as tecnologias mais avançadas como 
clonagem e transgenia (VAN WAG TENDONK-DE LEEUW, 2006; GONÇALVES et al., 2008).

Os oócitos podem ser recuperados de animais jovens (novilhas pré-púberes) e de animais gestantes nos primeiros três meses de gestação (VAN WAG TENDONK-DE LEEUW, 2006; WATANABE et al., 2008). Alem disso, vários touros podem ser usados na FIV nos oócitos de uma única aspiração comparado à colheita de embriões que quando se utiliza mais de um touro é necessário o teste de parentesco, maximizando o ganho genético e minimizando a endogamia (VAN WAG TENDONK-DE LEEUW, 2006).

\subsubsection{Aspiração folicular}

Após o desenvolvimento da OPU alguns estudos foram sendo realizados relacionados aos fatores técnicos e biológicos. O método de obtenção dos oócitos possui considerável impacto sobre a quantidade e morfologia dos complexos cumulus oophorus, e conseqüentemente sobre a competência para o desenvolvimento (BOLS et al., 1997). Fatores mecânicos devem ser considerados para otimizar esta técnica como tamanho e tipo da agulha, pressão do vácuo e frequência do transdutor (BECKER et al., 1996; SENEDA et al., 2003). Os resultados disso trouxeram melhora na qualidade dos oócitos recuperados pela redução dos oócitos desnudos (os quais falham em produzir embriões), mas não teve sucesso significativo na melhora no número total de oócitos recuperados por sessão. No entanto, houve uma melhoria na técnica quando se substituiu a agulha de aço inoxidável descartável de $50 \mathrm{~cm}$ por uma agulha hipodérmica curta estéril facilmente trocável entre diferentes vacas doadoras, reduzindo o risco de contaminação entre diferentes animais. A vantagem adicional é que as agulhas descartáveis são baratas, não precisam ser limpas, são facilmente manipuladas e tem pequeno diâmetro, o qual minimiza o tempo que o complexo cumulus oócito (CCOs) fica exposto ao ambiente desfavorável (SENEDA et al., 2002; VAN WAG TENDONK-DE LEEUW, 2006).

Agulhas com calibre menores que $21 \mathrm{G}$ e maiores que $17 \mathrm{G}$ não devem ser utilizadas, pois impossibilitam a punção do complexo cumulus oophorus (CCOs) ou dificultam a aspiração de foliculos de menor diâmetro (HASHIMOTO et al., 1999). 
As agulhas de diâmetro maiores de $18 \mathrm{G}$ estão relacionadas a maiores taxas de recuperação de oócitos, embora com maior percentual de oócitos desnudos, alem de maior dano ao estroma ovariano e maior quantidade de sangue no líquido aspirado. Já as agulhas de diâmetro menor que 19G apresentaram índices reduzidos na recuperação de oócitos, possivelmente por ser mais lenta a sua aspiração do líquido folicular, no momento da punção (SENEDA et al., 2002). Segundo Bols et al. (1996) agulhas de menor calibre estão menos sujeitas a variação na velocidade de fluido aspirado por minuto do que agulhas com calibre interno maior. Agulhas de menor diâmetro resultam na maior recuperação de CCOs de melhor qualidade e menor percentual de oócitos total ou parcialmente desnudos (BOLS et al. 1996.; HASHIMOTO et al., 1999). Agulhas com bisel mais longo demonstraram ter uma maior taxa de recuperação de estruturas e melhor qualidade de oócitos (BOLS et al., 1997).

Experimentos relacionados a pressão do vácuo na OPU realizados por Bols et al. (1996) descreve, que baixas pressões como $50 \mathrm{mmHg}$, foram pouco eficientes para aspiração, enquanto que pressões acima de $120 \mathrm{mmHg}$ prejudicavam o revestimento do CCOs, o autor também descreve uma grande variação entre trabalhos, com valores de 40 a $400 \mathrm{mmHg}$. A pressão da bomba de vácuo também pode ser influenciada por outros fatores como, comprimento, diâmetro de conexões, altura da bomba de vácuo e diâmetro da agulha podendo estes também influenciar na pressão final exercida no oócito (SENEDA et al., 2002). Para quantificar a pressão final mais precisamente, Pieterse et al. (1988) sugeriram mensurar o vácuo em volume de fluido por minuto, mesmo assim ocorreram variações de 4,4 a $40 \mathrm{ml}$ por minuto. Gonçalves et al. (2008) descreve que a bomba de vácuo deve estar ajustada para aspirar um volume de $10 \mathrm{ml}$ de líquido por minuto.

Becker et al. (1996) relataram a recuperação de oócitos através de endoscopia e aspiração guiada pela ultrassonografia transvaginal, a qual naquela época vinha ganhando popularidade. E estes pesquisadores avaliaram a eficiência da técnica via ultrassonografia transvaginal e endoscopia quanto a recuperação dos oócitos e encontraram variações na recuperação dos oócitos entre os animais e entre o mesmo animal em diferentes sessões de recuperação, sendo que a taxa de recuperação variou de 0 a $70 \%$ via ultrassonografia e 0 a $76 \%$ via endoscopia.

A taxa de recuperação de oócitos por sessão guiada pela ultrassonografia transvaginal foi de $44 \%$ e através da endoscopia foi de $39 \%$ por sessão de aspiração (BECKER et al., 1996). De acordo com Seneda et al. (2003) os transdutores convexos são os mais utilizados na aspiração folicular transvaginal de bovinos. $\mathrm{O}$ autor descreve em seu experimento a utilização 
de uma alternativa de equipamento na aspiração folicular transvaginal com o uso de um transdutor linear, equipamento este mais utilizado na rotina de médicos veterinários em diagnóstico de gestação de bovinos, do que o transdutor convexo. E em seu experimento obteve resultados semelhantes quanto ao número de oócitos aspirados quando comparou os dois transdutores, sendo 5.4 para o convexo e 4.6 oócitos recuperados para o linear por procedimento de aspiração em animais da raça Blonde d'Quintane. Vários autores relatam o uso de transdutores com diferentes frequiências, $7.5 \mathrm{mHz}$ (BOLS et al., 1995), $6.5 \mathrm{MHz}$ (BUNGARTZ et al., 1995) e 5.0 MHz (HASLER et al., 1995).

Os fatores biológicos que foram investigados incluem a própria doadora, préestimulação hormonal, frequiência e experiência do aspirador e a equipe envolvida no procedimento. Assim como na colheita de embriões, na OPU, a vaca doadora também tem uma influencia de 20\% nos oócitos aspirados (VAN WAG TENDONK-DE LEEUW, 2006).

Por último e não menos importante, a experiência do operador tem um significante efeito sobre o número e qualidade dos oócitos obtidos e alguns treinamentos em combinações com a seleção dos operadores e ou assistentes podem auxiliar a melhorar os resultados (VAN WAG TENDONK-DE LEEUW, 2006).

\subsection{OVÁRIO MAMÍFERO}

O ovário mamífero é constituído pelas regiões cortical e medular, ou seja, a primeira contém folículos ovarianos em diferentes estágios de desenvolvimento, bem como corpos lúteos, albicans e hemorrágicos, a segunda esta localizada na porção mais interna do ovário, é constituída por tecido conjuntivo, algumas células musculares lisas, nervos, artérias e veias (CORMACK, 1991). A camada medular é responsável pela nutrição e sustentação do ovário (HAFEZ, 1996). Pequenos vasos sangüíneos estendem-se, a partir da medula, para dentro do córtex ovariano (CORMACK, 1991).

O ovário desempenha funções endócrina e exócrina ou gametogênica. A primeira é responsável pela produção e liberação de hormônios esteróides e diversos peptídeos, e a segunda responsável pela produção e liberação de oócitos (HAFEZ, 1996), a qual é exercida pela interação de dois fenômenos, a oogênese e a foliculogênese (SAUMANDE, 1991). 


\subsection{OOGÊNESE}

A oogênese em mamíferos é uma sequência de eventos através dos quais as células germinativas primordiais (CGP) desenvolvem-se e diferenciam-se até a formação do oócito haplóide (RÜSSE, 1983). Esta tem seu inicio na vida fetal, porém apenas alguns oócitos conseguem completar este processo meses ou anos mais tarde no animal quando adulto, após a fecundação (WASSARMAN, 1988). Nos ruminantes, a diferenciação e a multiplicação das oogônias, ocorre no desenvolvimento da vida fetal, ou seja, muito antes do parto (BANKS, 1992).

Após um processo marcado pelo crescimento celular e pela redistribuição de organelas citoplasmáticas, as CGP, dentro do ovário, multiplicam-se ativamente e transformam-se em oogônias (GORDON, 1994), iniciando a meiose e diferenciando-se em oócitos (HIRSHFIELD, 1991). A transformação de oogônia em oócito é marcada pela replicação final do DNA durante o estágio de pré-leptóteno (interfase que segue a última divisão mitótica da oogônia), preparando a célula para a divisão meiótica (GORDON, 1994).

Os oócitos formados começam a primeira divisão meiótica, passando pelos estágios da prófase I; leptóteno, zigóteno, paquíteno e diplóteno (HIRSHFIELD, 1991). No estágio de diplóteno, também conhecido como estágio de dictióteno ou de vesícula germinativa (GORDON, 1994), ocorre a primeira interrupção da meiose e formação dos oócitos primários (MOORE; PERSAUD, 1994). Por vários anos, estes oócitos permanecem nesse estágio até que a maturidade sexual seja alcançada e comecem os ciclos reprodutivos, ou melhor, permanecem no estágio de prófase I até imediatamente antes da ovulação, quando então a meiose é retomada (MOORE; PERSAUD, 1994), passando do estado de vesícula germinativa para diacinese (HIRSHFIELD, 1991). Em seguida, ocorre o rompimento da vesícula germinativa, progressão para metáfase I, anáfase I e telófase I, exclusão do primeiro corpúsculo polar e formação do oócito secundário (BETTERIDGE et al., 1989). O núcleo do oócito entra na segunda divisão meiótica, avançando apenas até a metáfase II, quando então esta divisão é interrompida (GORDON, 1994). A divisão só será retomada caso ocorra a fertilização com o encontro de um espermatozóide com um oócito, ocorrendo então a exclusão do segundo corpúsculo polar e a formação do oócito haplóide (MOORE; PERSAUD, 1994). 


\subsection{FOLICULOGÊNESE}

A foliculogênese é um evento iniciado na vida pré-natal na maioria das espécies. Ela caracteriza-se pela formação, crescimento e maturação folicular, o qual se origina com a formação do folículo primordial e culmina com o desenvolvimento do folículo pré-ovulatório ou de De Graaf (SAUMANDE, 1991; MOORE; PERSAUD, 1994). A oogênese e a foliculogênese ocorrem simultaneamente, quando o oócito está entre as fases de prófase I à metáfase II. A foliculogênese pode ser dividida em duas fases: 1) Fase pré-antral, que é subdividida em ativação dos folículos primordiais e crescimento dos folículos primários e secundários; 2) Fase antral, subdividida em crescimento inicial e terminal dos folículos terciários. Ainda na fase pré-natal, alguns folículos primordiais são ativados, crescem e diferenciam-se em folículos primários, secundários e terciários (RÜSSE, 1983). Somente na vida pós-natal, sob efeito hormonal, os folículos podem atingir o estágio pré-ovulatório (FORTUNE, 1994).

A população folicular ovariana é bastante heterogênea (SAUMANDE, 1991). De acordo com seu grau de evolução, os folículos podem ser divididos em: a) folículos préantrais ou não cavitários e b) folículos antrais ou cavitários (HULSHOF et al., 1994).

\subsubsection{Folículos pré-antrais}

Os folículos pré-antrais compreendem cerca de $90 \%$ da população folicular do ovário mamífero (ERICKSON, 1986) e constituem o estoque de gametas femininos durante a vida reprodutiva do animal (LIU et al., 2001). Esta classe folicular compreende os folículos primordiais, primários e secundários (HULSHOF et al., 1995), os quais podem ser diferenciados basicamente pelo número e forma das camadas de células da granulosa que circundam o oócito. O crescimento folicular inicia-se com a ativação dos folículos primordiais, sendo caracterizado por mudanças na forma das células da granulosa de pavimentosa para cúbica, proliferação destas células e aumento de tamanho do oócito (HIRSHFIELD, 1991). 
Os folículos primordiais, também denominados de folículos de reserva ou quiescentes, compreendem cerca de $90 \%$ a $95 \%$ de toda a população folicular presente no ovário (ERICKSON, 1986) e são constituídos por um oócito central circundado por uma camada de células da pré-granulosa de forma pavimentosa. O diâmetro médio dos folículos primordiais varia muito de acordo com a espécie animal, sendo 35,2 $\mu \mathrm{m}$ nos bovinos (BRAW-TAL; YOSSEFI, 1997).

Os folículos primários são constituídos por um oócito central circundado por uma única camada de células da granulosa de forma cúbica (HULSHOF et al., 1994). Com o seu desenvolvimento, o oócito aumenta de volume, ao mesmo tempo em que surge ao seu redor a zona pelúcida (GEORGE et al., 1998). Na espécie bovina, o diâmetro médio encontra-se em torno de 55,06 $\mu \mathrm{m}$ (BRAW-TAL; YOSSEFI, 1997).

Os folículos secundários são caracterizados histologicamente por um oócito central circundado por duas ou mais camadas de células da granulosa de forma cúbica. Neste estágio, a zona pelúcida se torna evidente, os mais avançados apresentam as fibras do tecido conjuntivo organizadas paralelamente à membrana basal para formar a camada de células tecais (VAN DEN HURK et al., 1997). Na espécie bovina, estes folículos possuem um diâmetro médio de 165,5 ㅆm (BRAW-TAL, YOSSEFI, 1997).

\subsubsection{Folículos antrais}

Folículos antrais são classificados como folículos terciários e folículos de De Graaf, denominados ainda maduros ou pré-ovulatórios. Os folículos terciários são constituídos de um oócito circundado pela zona pelúcida, várias camadas de células da granulosa, uma pequena cavidade antral, formada pelo acúmulo de líquido durante a evolução do folículo secundário, uma membrana basal e duas camadas de células tecais conhecidas como teca interna e externa (GORDON, 1994). O folículo de De Graaf ou pré-ovulatório, que representa o estágio terminal do desenvolvimento folicular (HULSHOF et al., 1994), apresenta uma grande cavidade preenchida pelo líquido folicular e o oócito aderido à parede do folículo pelas células foliculares. O conjunto de células que envolve o oócito é denominado corona radiata (BANKS, 1992; GEORGE et al., 1998). O diâmetro máximo do folículo dominante pode variar em fêmeas Bos indicus de 11,3 a 12,1 mm. Já em fêmeas Bos taurus com duas ondas 
de crescimento folicular são descritos diâmetros de 17,1 e 16,5 mm para a primeira e segunda onda respectivamente (GINTHER et al., 1989; FIGUEIREDO et al., 1997).

\subsubsection{Ativação e crescimento dos folículos pré-antrais}

Para que os folículos primordiais se desenvolvam é necessário que eles sejam ativados. Este processo de ativação se dá pela passagem dos folículos do pool de reserva (primordiais) para o pool de folículos em crescimento (primário, secundário, terciário e/ou pré-ovulatório (RUSSE, 1983). O primeiro sinal de ativação é a retomada da proliferação das células da granulosa, ou seja, o folículo primordial, o qual se apresenta circundado por uma camada de células da granulosa de formato pavimentoso (BRAW-TAL; YOSSEFI, 1997) transforma-se em folículo primário (VAN DE HURK et al., 1997), circundado por somente uma camada de células cúbicas. Além da mudança da forma das células da granulosa, os volumes citoplasmático e nuclear do oócito aumentam consideravelmente (HIRSHFIELD, 1991). O conhecimento sobre os fatores e mecanismos envolvidos na regulação e ativação dos folículos primordiais é escasso. Entretanto, existem hipóteses de que o número de folículos primordiais que deixa o pool de reserva seja predeterminado e, que o FSH (hormônio folículo estimulante) tenha ação sobre essa ativação (BETTERIDGE et al., 1989).

O FSH parece estar envolvido na proliferação e diferenciação das células da granulosa in vitro. Aparentemente, níveis basais de FSH são necessários para o desenvolvimento de pequenos folículos (VAN DEN HURK et al., 1997). Hirshfield (1991) sugeriu que a ativação e o crescimento dos folículos primordiais devem ser controlados tanto por fatores endócrinos (gonadotrofinas), como por fatores intraovarianos (fatores de crescimento). A ativação continua assim que é iniciada, independentemente da fase do ciclo, idade e gestação (JEWGENOW; PITRA, 1993). 


\subsection{POPULAÇÃO FOLICULAR EM OVÁRIOS MAMÍFEROS}

Na espécie bovina, a população folicular está em torno de 235.000 folículos por ovário (BETTERIDGE et al., 1989). Nas espécies caprina, ovina e na mulher, este número foi estimado em 37.646 (LUCCI et al., 1999), 160.000 (DRIANCOURT, 1991) e 2.000.000 (ERICKSON, 1986), respectivamente. No entanto, vários fatores, além da variação individual, podem afetar o número de folículos presentes no ovário. Dentre eles, podem ser citados raça (CAHILL et al., 1979), idade (ERICKSON, et.al., 1996; RÜSSE, 1983), níveis hormonais (PETERS, 1976), genética (ERICKSON, 1986), estado reprodutivo (ERICKSON et al., 1976) e nutricional do animal (SCARAMUZZI et al., 1993).

\subsection{ATRESIA FOLICULAR}

Há aproximadamente $2 \times 10^{6}$ células germinativas no tecido ovariano de fetos bovinos no final do primeiro trimestre de gestação, mas este numero diminui drasticamente durante 0 período final de gestação ate o nascimento quando a ativação folicular tem inicio. A ovulação e atresia são os dois principais processo envolvidos na diminuição do pool de reserva de folículos pré-antrais do tecido ovariano (SILVA-SANTOS et al., 2011).

Os folículos ovarianos pré-antrais representam cerca de $90 \%$ da população folicular (SAUMANDE, 1991) e são responsáveis pela constante renovação de folículos antrais no ovário (IRELAND, 1987). No entanto, ao redor de 99,9\% dos folículos de um ovário não ovulam, mas sofrem um processo fisiológico conhecido como atresia, que causa a morte do folículo. Este processo acomete todas as espécies domésticas e pode ocorrer em qualquer estágio do desenvolvimento folicular (IRELAND, 1987), sendo mais evidente nos folículos antrais, especialmente quando estes atingem um tamanho no qual ocorre a diferenciação terminal das células da granulosa e da teca (LUSSIER et al.,1987; HIRSHFIELD, 1988; SAUMANDE, 1991;). Vários são os fatores que podem influenciar este processo, como idade, ciclo reprodutivo, gestação, lactação e nutrição (INGRAN 1962).

Independentemente da fase na qual ocorre e, apesar de ser um fenômeno natural, a atresia reduz de maneira significativa o número de oócitos viáveis durante a vida reprodutiva 
de um animal, fazendo com que o potencial do ovário seja fracamente aproveitado (INGRAN, 1962).

\subsection{PIVE NOS DIAS DE HOJE}

Mundialmente, o número de embriões produzidos in vitro aumentou consideravelmente, subindo em 74.000 (26\%). O número de embriões transferidos in vitro no mundo mostrou um crescimento de 11\% (340.000) em 2010 comparado a 306.000 em 2009 (STROUD, CALLESEN, 2012). A América do Sul foi responsável por 59\% (268.000) deste aumento em 2010, comparada a 68\% em 2009. O Brasil, pais líder mundial na produção de embriões in vitro, produziu 264.263 embriões in vitro. Destes, foram transferidos 252.048 embriões produzidos in vitro a fresco e 12.214 congelados. Ainda em 2010, atrás do Brasil se encontraram países como Panamá (segundo lugar na produção de embriões in vitro - 2.905) e o Uruguai (terceiro lugar - 850 embriões in vitro). Apenas $7 \%$ dos embriões in vitro transferidos no mundo eram congelados em 2010 (STROUD; CALLESEN, 2012).

A indústria da PIV tem sido constantemente melhorada nas últimas décadas, ou seja, o numero de embriões produzidos in vivo ou in vitro estão similares. O uso da PIV no Brasil tem apresentado grande impacto quando comparada à colheita de embriões e a razão para isso é que os Zebuínos (Bos indicus) possuem mais folículos no tecido ovariano e consequentemente mais oócitos quando da realização da aspiração folicular comparado com Bos taurus. Ainda não está clara a explicação do porquê desta diferença. De qualquer modo, no Brasil, a maioria das informações referentes à FIV estão relacionadas à raça Nelore (Bos indicus) o qual representa $80 \%$ do rebanho brasileiro (200 × $10^{6}$ animais) (PONTES et al., 2010).

As fêmeas Bos indicus tem mais ondas foliculares, mais folículos por onda e maior população folicular de folículos antrais $<5 \mathrm{~mm}$ de diâmetro que as fêmeas Bos taurus. Alem disso, os folículos dominantes e corpos lúteos são pequenos e o estro é mais curto nos $B$. Indicus comparado às fêmeas B. taurus (SILVA-SANTOS et al., 2011).

Silva-Santos et al. (2011) relatam que foi possível recuperar 251 oócitos em uma única sessão de OPU em uma vaca da raça Nelore e há reportações acima de 564 oócitos de uma fêmea da mesma raça. Alem da quantidade de oócitos (564) a qualidade destes oócitos 
coletado também é impressionante, sendo a maioria classificados como oócitos viáveis (77\%, grau I, II e III). A média do número de oócitos aspirados por sessão de OPU em vacas da raça Nelore é reportada entre 18 a 25, ou seja, três a quatro vezes maiores que a média descrita para as vacas $B$. taurus.

A raça Nelore possui aptidão à produção de carne e, além disso, está muito adaptada às condições tropicais do território Brasileiro. Adicionalmente, tem-se observado um grande interesse em raças zebuínas como a Gir considerando a sua adaptabilidade em produzir grandes quantidades de leite mesmo em condições de estresse como pouca disponibilidade de forrageira, parasitismos e altas temperaturas (PONTES et al., 2010).

Estas características são mantidas no cruzamento entre a raça Gir e Holandês, produto denominado "Girolanda", que está presente na América Central e do Sul. Recentemente, a produção in vitro de embriões tem sido considerada em doadoras da raça Girolanda, principalmente quando se fez o uso de sêmen sexado melhorando a eficiência da FIV e da técnica em produzir fêmeas quando o intuito da produção é leite (PONTES et al., 2010).

De acordo com Silva-Santos et al. (2011) o numero de oócitos recuperados pela OPU em fêmeas Bos taurus indicus é duas a quatro vezes maior do que em fêmeas Bos taurus taurus. Porém, quando se comparou a população de folículos pré-antrais destas fêmeas, notou-se que o número destes folículos variou consideravelmente entre indivíduos de mesma categoria e entre as raças, não sendo este o provável fator que interfira na maior taxa de recuperação oocitária nos Bos indicus, mas talvez algum mecanismo envolvido no controle do desenvolvimento folicular pós-estágio pré-antral. 


\section{OBJETIVOS}

\subsection{OBJETIVO GERAL}

O objetivo do presente trabalho foi comparar a produção in vitro de embriões de doadoras das raças Nelore (CEIP e não CEIP), Brangus e Girolando.

\subsection{OBJETIVOS ESPECÍFICOS}

- Obter dados sobre a produção in vitro de embriões em raças sintéticas adaptadas ao clima tropical, devido a escassez de dados na literatura .

- Obter a produção total de oócitos, oócitos viáveis, embriões e taxas de prenhes das diferentes doadoras das raças Nelore (CEIP e não CEIP), Brangus e Girolando.

- Comparar os parâmetros coletados entre as diferentes raças e pela média de procedimentos de OPU. 


\section{HIPÓTESES}

A raça Nelore apresenta um número maior de ondas foliculares por ciclo ovulatório (três ondas foliculares), sendo assim, será recrutado um maior número de folículos por ciclo e consequentemente será observada uma produção mais expressiva de oócitos e consequentemente de embriões, que nas raças sintéticas.

Os animais da raça Girolando e Brangus, por se tratarem de animais sintéticos com maior grau de sangue taurino (5/8 Bos taurus x 3/8 Bos indicus), apresentam um número menor de ondas foliculares por ciclo ovulatório (duas ondas foliculares) ocasionando um menor recrutamento folicular por ciclo estral e consequentemente menor número de oócitos e embriões produzidos in vitro, que animais da raça Nelore. 


\section{MATERIAL E MÉTODOS}

\subsection{LOCAL}

O experimento foi realizado no período de janeiro de 2010 a dezembro de 2012 no Laboratório de Reprodução Animal da Agropecuária Laffranchi, localizada na cidade de Tamarana, estado do Paraná, Brasil.

5.2 ANIMAIS

Foram utilizadas doadoras das raças Nelore (não CEIP, Bos indicus, $\mathrm{n}=34$ ), Nelore (CEIP, Bos indicus, $\mathrm{n}=22$ ), Brangus (5/8 Bos taurus $x$ 3/8 Bos indicus, $\mathrm{n}=64$ ) e Girolando (5/8 Bos taurus x 3/8 Bos indicus, $\mathrm{n}=52$ ), saudáveis, não gestantes, ciclando, nulíparas e multíparas, previamente selecionadas e de alto valor genético. Estes animais apresentavam escore corporal de 3,5 0,5 (escala de 1 - 5) (LOWMAN et al., 1976), com peso médio de $500 \pm 50 \mathrm{~kg}$ e idade média de $5 \pm 2,3$ anos (3-7 anos). Todas as doadoras foram avaliadas por palpação e ultrassonografia transretal anterior a cada um dos procedimentos de OPU e as mesmas apresentavam atividade ovariana regular.

Os animais permaneceram na mesma propriedade durante a realização do experimento. As doadoras da raça Nelore e Brangus permaneciam em pastagem mista de Brachiaria Brizantha e Estrela Africana (Cynodon nlemfuensis var. nlemfuensis), com sal mineral e água ad libitum. Já as doadoras da raça Girolando permaneciam na mesma pastagem, porém, com suplementação de silagem de milho acrescida de ração comercial com 22\% PB (para cada 3 litros de leite produzido, fornecia-se $1 \mathrm{~kg}$ de ração), além de sal mineral e água ad libitum. 
Nenhuma hormonioterapia exógena foi administrada para estimular a produção ou sincronização de onda folicular. Todos os animais foram submetidos à OPU totalizando 397 procedimentos, com uma média de 2,3 $\pm 0,7$ (2,1-3,1) OPU por vaca. Alguns animais foram aspirados diversas vezes, outros foram submetidos a apenas um procedimento. As doadoras foram submetidas à OPU sem uma escala específica ou predeterminada, sendo que os procedimentos foram feitos de forma aleatória. As aspirações quando repetidas, foram realizadas com no mínimo 15 dias de intervalo entre elas, em qualquer estágio do ciclo estral. As doadoras da raça Nelore foram submetidas a 104 OPUs, as Nelore CEIP à 52 OPUs, as Brangus à 133 OPUs e as da raça Girolando à 108 OPUs.

\subsection{PREPARO DAS DOADORAS}

Antes de cada procedimento de OPU, as fezes foram removidas do reto e a área perineal foi limpa com água de torneira e álcool 70\%. Em seguida, cada vaca recebeu anestesia epidural com $5 \mathrm{ml}$ de lidocaína a 2\% (Anestésico L, Pearson, São Paulo, SP, Brasil) para diminuir o peristaltismo e desconforto.

\subsection{ASPIRAÇÃO FOLICULAR}

O procedimento usado para aspiração folicular foi o mesmo, previamente descrito por Seneda et al. (2001). Brevemente, cada folículo visível foi aspirado usando um ultrassom em tempo real modo B (DP- 2200 vet, Mindray, Shenzhen, China), com um transdutor convexo de 6,5 MHz (65C15EAV Micro-convexo- Mindray, Shenzhen, China), o mesmo foi adaptado para uma guia de aspiração transvaginal específica para o sistema reprodutor bovino. A punção dos oócitos nos folículos ovarianos foi feita com a utilização de uma agulha $18 \mathrm{G}$ 
(WTA ${ }^{\circledR}$ - São Paulo, Brasil) conectada a um sistema de aspiração (WTA ${ }^{\circledR}$ - São Paulo, Brasil) acoplado a um tubo falco cônico de $50 \mathrm{ml}$ (Corning, Acton, MA, USA) de silicone $(0,8 \mathrm{~m} ; 2$ $\mathrm{mm}$ ), para a punção dos folículos este sistema transmite uma pressão que é determinada por uma bomba de vácuo digital BV 003i (WTA ${ }^{\circledR}$ - São Paulo, Brasil) ajustada para uma pressão de $90 \mathrm{mmHg}$.

\subsection{PRODUÇÃO IN VITRO DOS EMBRIÕES}

Imediatamente depois da recuperação, o material aspirado foi lavado e filtrado através de um filtro de embriões (WTA ${ }^{\circledR}$ - São Paulo, Brasil) com solução de PBS (phosphate buffer solution - Nutricell, Campinas, SP, Brasil). Os complexos cúmulos oócitos (CCOs) foram classificados de acordo com a presença de células no cúmulus e a qualidade do oócito usando o critério que segue: bom, mais que três camadas de células no cúmulus; regular, uma única camada de células no cúmulus; desnudo, parcialmente coberto por células do cúmulus ou sem cúmulus e atrésico cumulus oócitos escuro com sinais de degeneração do citoplasma (Seneda et al., 2001). Os oócitos bons e regulares foram considerados viáveis e utilizados, e os folículos atrésicos foram descartados. Anteriormente à maturação in vitro (MIV), o CCOs foram lavados tres vezes em TCM 199 HEPES (Gibco Life Technologies, Grand Island, NY, USA) suplementado com SFB a $5 \%$ e $50 \mu \mathrm{g} / \mathrm{ml}$ de sulfato de gentamicina e, em seguida foram lavados uma vez em bicarbonato TCM 199 (Gibco Life Technologies) suplementado com SFB a 10\%, $5 \mu$ g hormônio luteinizante (LH-Ayerst, Rouses Point, NY, USA), $0.5 \mu \mathrm{g}$ de hormônio folículo estimulante (FSH-Folltropin, Vetrepharm, Belleville, ON, Canada), $1 \mu \mathrm{g}$ estradiol (estradiol-17ß, Sigma E-8875), $2.2 \mu \mathrm{g}$ piruvato (Sigma P-4562) e $50 \mu \mathrm{g}$ de gentamicina/mL de meio.

O CCOs de cada categoria foi separadamente cultivado por 22 horas em $100 \mu \mathrm{de}$ gotas de meio de maturação sob óleo mineral (D’Altomare, Santo Amaro, SP, Brasil) a $38{ }^{\circ} \mathrm{C}$ e 5\% de $\mathrm{CO}_{2}$ em ar (BLASCHI et al., 2004; PEIXOTO et al., 2006). Foram usados sêmen congelado de touros das raças Girolando $(n=14)$, Brangus $(n=9)$, Nelore $(n=9)$ e Nelore CEIP ( $n=5$ ) de fertilidade conhecida (baseado em utilizações prévias na FIV). Para a FIV, as palhetas foram descongeladas por 30 segundos em banho Maria a $37{ }^{\circ} \mathrm{C}$. Os espermatozóides 
foram lavados por centrifugação a 800 "g" por 5 minutos através de 90-45\% de gradiente de Percoll, após a retirada do sobrenadante foi adicionado $1 \mathrm{ml}$ de meio TALP, e uma nova centrifugação de 2 minutos a 200 "g" foi utilizada para remover o excedente do Percoll. Os espermatozóides foram capacitados usando heparina $(20 \mu \mathrm{g} / \mathrm{mL})$ e a motilidade estimulada com a adição de $40 \mu \mathrm{L} / \mathrm{mL}$ de penicilamina, hipotaurina e epinefrina (PARRISH et al., 1986). Após a avaliação da motilidade, a concentração dos espermatozóides foi ajustada a $2 \times 10^{6}$ espermatozóides móveis $/ \mathrm{mL}$ e cada gota de fertilização recebeu $4 \mu \mathrm{L}$ de espermatozóide (concentração final de $1 \times 10^{5}$ espermatozóides/gota) (SENEDA et al., 2001). Após a maturação, o CCOs foram lavados três vezes no meio pré-fertilização TCM 199 suplementado com 25 mM HEPES (Gibco Life Technologies, Grand Island, NY, USA) e 0.3\% SFB (Sigma A-9647), e foram lavados uma vez no meio de fertilização TALP suplementado com 10 $\mu \mathrm{g} / \mathrm{mL}$ de heparina e $160 \mu \mathrm{L}$ solução PHE (PARRISH et al., 1986; BAVISTER et al., 1989).

Os zigotos que tinham seus cúmulus foram previamente removidos e transferidos a gotas de $100 \mu \mathrm{L}$ de meio de cultivo de embriões (SOFaa BSA, containing $8 \mathrm{mg} / \mathrm{mL}$ SFB e 1 mM de glutamina). Após a FIV, os oócitos foram desnudados com auxílio de um micropipetador de $50 \mu \mathrm{l}$ e trnasferidos para meio de cultivo in vitro (CIV) fluido de oviduto sintético (SOF), suplementado com aminoácidos essenciais (BME) e não essenciais (MEM), 0,34mM de mioinositol, $3 \%$ de soro fetal bovino, $4 \mathrm{mg} / \mathrm{ml}$ de BSA, ITS ( insulina $5 \mu \mathrm{l} / \mathrm{ml}$ e glutamina $0,09 \mathrm{mg} / \mathrm{ml}$ ), em gotas de $100 \mu \mathrm{l}$ de meio com monocamada de células somáticas (cumulus). $\mathrm{O}$ cultivo in vitro foi feito em estufa de $\mathrm{CO}_{2}$, a $38,5^{\circ} \mathrm{C}$, em atmosfera de $5 \%$ de $\mathrm{CO}_{2}$ em ar. Os embriões permaneceram nestas condições ate o momento da transferência nas receptoras.

A osmolaridade foi mantida de 270 a 280 mOsmol e o pH foi de 7,4. A taxa de embriões foi obtida do total de oócitos viáveis aspirados. Todos os embriões foram transferidos em receptoras de embrião no Dia 7 do embrião.

\subsection{PROTOCOLO DE TRANSFERÊNCIA DOS EMBRIÕES}

As receptoras utilizadas para a transferência dos embriões produzidos in vitro eram mestiças das raças Pardo Suiço e Nelore, saudáveis sendo novilhas (15-23 meses de idade) e 
vacas ( 24 a 48 meses de idade). O critério para a escolha da receptora foi a presença de ciclos ovarianos regulares, escore corporal apropriado e serem saudáveis. Após a avaliação os animais aptos foram submetidos a protocolo de TETF (transferência de embrião em tempo fixo), que consistiu nos procedimentos seguintes, D0- colocação de implante intravaginal com liberação lenta de progesterona (DIB ${ }^{\circledR}$ - Syntex, Argentina) e aplicação de $2 \mathrm{mg}$ de Benzoato de estradiol (Gonadiol ${ }^{\circledR}$ - Syntex, Argentina), D8- retirada do implante de progesterona com aplicação de 0,5 mg de PGF $2 \alpha$ (Ciosin $^{\circledR}$ - Ouro Fino, Brasil), 400 UI de ECG (Folligon ${ }^{\circledR}$ Intervet, Holanda), 0,6 mg de cipionato de estradiol ( ECP $^{\circledR}$ - Ouro Fino, Brasil), a transferência de embriões em tempo fixo era realizado no dia 17 do protocolo somente nas receptoras que apresentavam corpo lúteo (CL) ovariano, assim o embriões eram depositados por via transcervical no corno uterino ipsilateral ao CL apresentado no ovário. O diagnóstico gestacional era realizado através de ultrassonografia transretal no dia 30 de gestação.

\subsection{ANÁLISE ESTATÍSTICA}

As comparações entre proporções foram feitas pelo teste de Qui-quadrado. Dados objetivos foram verificados para normalidade pelo teste de Kolmogorov-Smirnov. Dados não normais foram transformados para adquirirem normalidade (ex. escala logarítmica). Após verificação da normalidade, análise de variância foi feita com o uso do programa SAS (GLM procedure; version 9.2; SAS Institute, Inc., Cary, NC) para determinação dos efeitos principais e de interação. Teste $t$-student foi utilizado para localizar diferenças entre médias dentro do mesmo grupo ou entre grupos quando efeitos principais e/ou de interação foram significativos. Probabilidade de $P \leq 0.05$ indicou significância. 


\section{RESULTADOS}

Das 172 doadoras que foram submetidas a 397 sessões de OPU, foi recuperado 7335 oócitos (18.4 oócitos/OPU), dos quais resultaram em 3597 oócitos viáveis (49\%), obtendo-se 969 embriões (26.9\%), dos quais 922 foram transferidos em receptoras previamente selecionadas, resultando em 266 prenhezes (taxa de prenhes 28.9\%). Os resultados descritos também estão ilustrados na tabela 1.

Do total de doadoras 64 fêmeas eram da raça Brangus, as quais foram submetidas a 133 sessões de OPU, recuperando-se 2139 oócitos, produzindo 967 oócitos viáveis (45.2\%), os quais resultaram em 272 embriões $(28.1 \%$ ) e 241 foram transferidos, obtendo-se 81 prenhezes $(33.6 \%)$ aos 30 dias de gestação. Na raça Girolando, 52 fêmeas foram submetidas à aspiração folicular, totalizando 108 sessões de OPU, as quais foram recuperados 1806 oócitos. Destes, 972 foram considerados viáveis (53.8\%) e resultaram na produção de 251 embriões (25.8\%), os quais foram transferidos 245, obtendo-se 61 prenhezes (24.9\%) aos 30 dias de gestação. Com relação às doadoras da raça Nelore CEIP, 22 fêmeas foram submetidas a 52 sessões de OPU, recuperando-se 1850 oócitos. Destes, 842 foram considerados viáveis (45.5\%), resultando em 214 embriões (25.4\%), do quais todos foram transferidos, obtendo-se 61 prenhezes $(28.5 \%)$ aos 30 dias de gestação. Na raça Nelore (não CEIP) foram aspiradas 34 fêmeas, as quais foram submetidas a 104 sessões de OPU, recuperando-se 1540 oócitos sendo 816 considerados viáveis (53.0\%), os quais resultaram na produção de 232 embriões (28.4\%), sendo transferidos 222 dos quais se obteve 63 prenhezes (28.4\%) aos 30 dias de gestação (Tabela 1). 
Tabela 1- Resultados gerais e individuais por raça nas aspirações das raças Brangus, Girolando, Nelore (CEIP) e Nelore (não CEIP).

\begin{tabular}{|c|c|c|c|c|c|c|}
\hline Raça & Brangus & Girolando & $\begin{array}{l}\text { Nelore } \\
\text { CEIP }\end{array}$ & $\begin{array}{c}\text { Nelore } \\
\text { não CEIP }\end{array}$ & $\boldsymbol{P}$ & Total \\
\hline Doadoras & 64 & 52 & 22 & 34 & & 172 \\
\hline $\begin{array}{c}\text { Aspirações } \\
\text { realizadas (OPU) }\end{array}$ & 133 & 108 & 52 & 104 & & 397 \\
\hline $\begin{array}{l}\text { Oócitos } \\
\text { recuperados } \\
\text { (total) }\end{array}$ & 2139 & 1806 & 1850 & 1540 & & 7335 \\
\hline $\begin{array}{l}\text { Oócitos viáveis } \\
\text { (total) }\end{array}$ & 967 & 972 & 842 & 816 & & 3597 \\
\hline $\begin{array}{l}\text { \% de oócitos } \\
\text { viáveis }\end{array}$ & $45.2^{\mathrm{a}}$ & $53.8^{\mathrm{b}}$ & $45.5^{\mathrm{a}}$ & $\mathbf{5 3 . 0 ^ { b }}$ & 0,0001 & 49.0 \\
\hline $\begin{array}{l}\text { Embriões } \\
\text { produzidos } \\
\quad \text { (total) }\end{array}$ & 272 & 251 & 214 & 232 & & 969 \\
\hline $\begin{array}{l}\text { \% de embriões } \\
\text { produzidos / } \\
\text { oócitos viáveis }\end{array}$ & 28.1 & 25.8 & 25.4 & 28.4 & 0,3580 & 26.9 \\
\hline $\begin{array}{c}\text { Embriões } \\
\text { transferidos (TE) }\end{array}$ & 241 & 245 & 214 & 222 & & 922 \\
\hline $\begin{array}{c}\text { Prenhezes } \\
\text { positivas (total) }\end{array}$ & 81 & 61 & 61 & 63 & & 266 \\
\hline Taxa de prenhez & 33.6 & 24.9 & 28.5 & 28.4 & 0,2069 & 28.9 \\
\hline
\end{tabular}

Letras minúsculas diferentes sobrescritas indicam diferenças estatísticas significativas.

Em comparação com a média de produção de oócitos por procedimento de aspiração, obteve-se na raça Nelore CEIP uma diferença estatística significante de $(P<0.0001)$, comparado com as raças Brangus, Nelore (não CEIP) e Girolando, as quais não apresentaram diferenças estatísticas entre elas (Figura 1). 
Figura 1- Média da produção total de oócitos por sessão de OPU nas diversas raças.

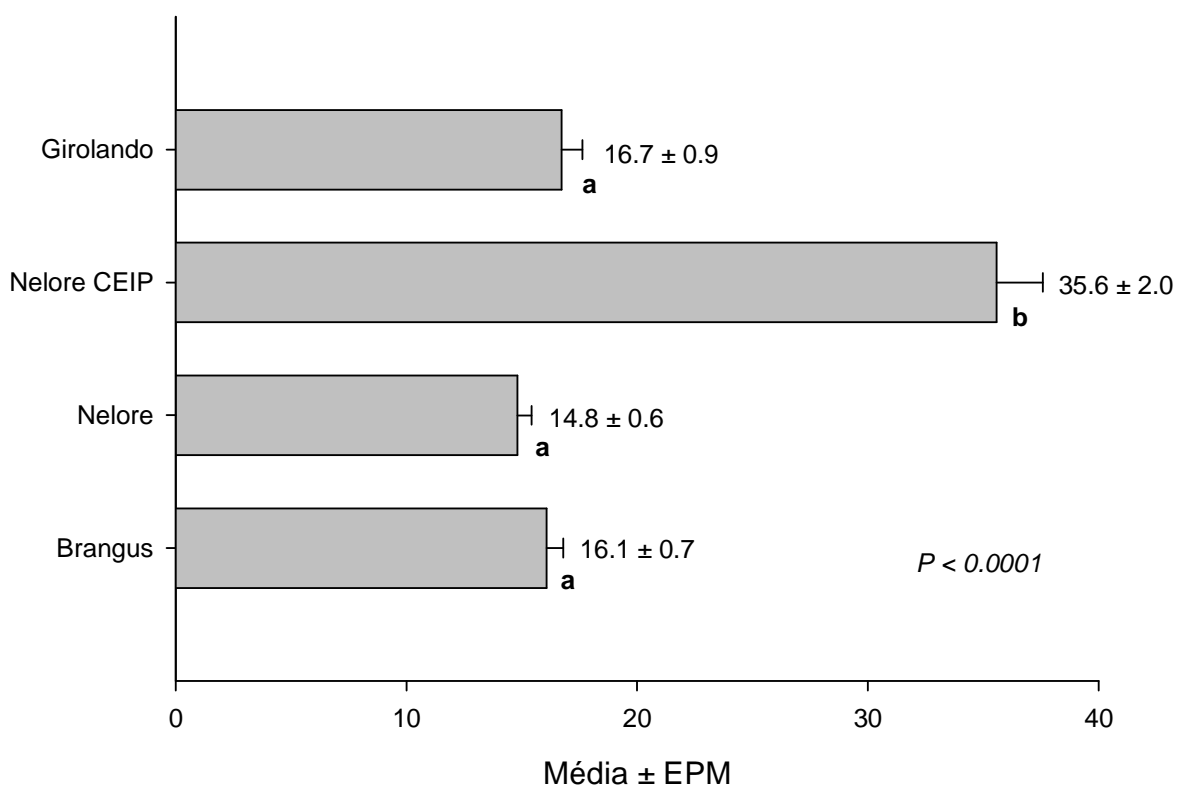

Letras minúsculas diferentes indicam diferenças estatísticas significativas.

Em comparação com o número de oócitos viáveis e não viáveis por sessão de OPU por raça, percebeu-se que nos animais da raça Nelore CEIP foram recuperados um maior número de oócitos viáveis e não viáveis, 16.2 e 19.38, respectivamente, o qual apresentou diferença estatística $(P<0000.1)$ quando comparado aos oócitos viáveis e não viáveis nas raças Brangus, Nelore (não CEIP) e Girolando (Figura 2). 
Figura 2- Comparação de óocitos viáveis x não viáveis por sessão de OPU.

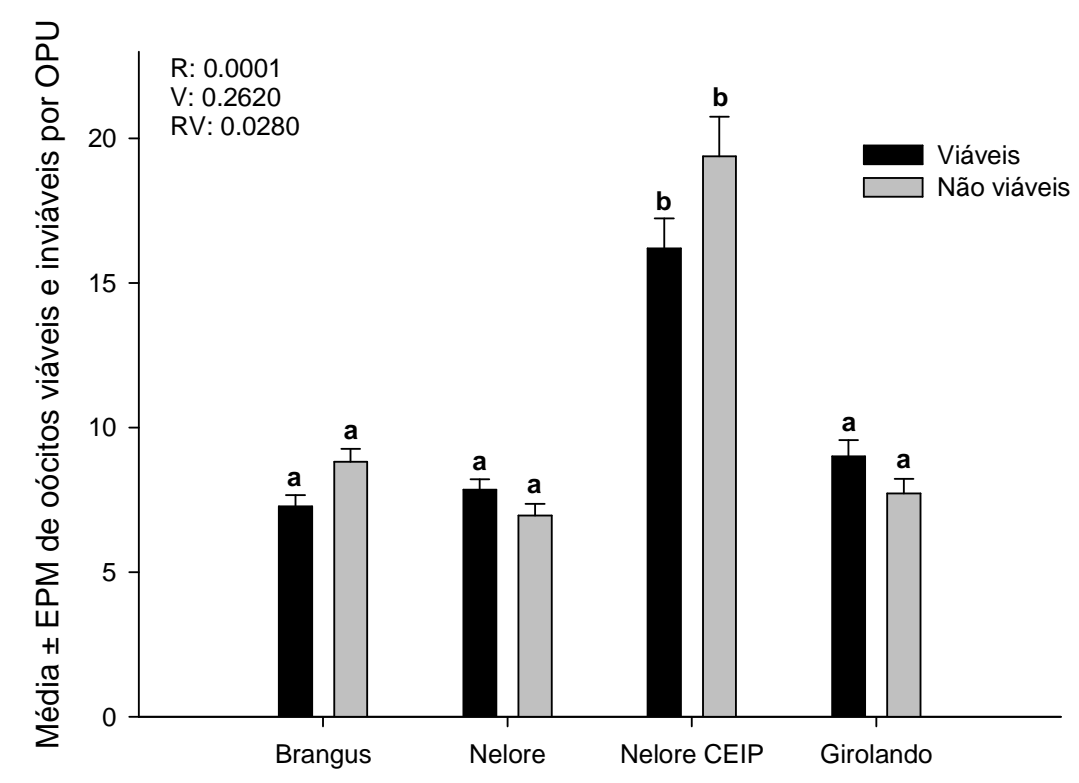

\begin{tabular}{|c|c|c|c|c|}
\hline $\begin{array}{c}\text { Média } \pm \\
\text { EPM }\end{array}$ & Brangus & Nelore & $\begin{array}{l}\text { Nelore } \\
\text { CEIP }\end{array}$ & Girolando \\
\hline Viáveis & $7,3 \pm 0,4$ & $7,9 \pm 0,4$ & $16,2 \pm 1,1$ & $9,0 \pm 0,6$ \\
\hline Não viáveis & $8,8 \pm 0,5$ & $7,0 \pm 0,4$ & $19,38 \pm 1,4$ & $7,7 \pm 0,5$ \\
\hline Total & $8,0 \pm 0,3$ & $7,4 \pm 0,3$ & $17,8 \pm 0,8$ & $8,4 \pm 0,4$ \\
\hline
\end{tabular}

Quando se comparou a porcentagem de oócitos viáveis entre todas as raças analisadas. Os resultados encontrados foram iguais estatisticamente para as raças Brangus (45.2\%) e Nelore CEIP (45.5\%) e o mesmo aconteceram com as raças Nelore (não CEIP) (53.0\%) e Girolando $(53.8 \%)$. Porém, foram encontradas diferenças significativas $(\mathrm{P}<0.0001)$ quando se comparou a porcentagem de oócitos viáveis entre as raças Brangus e Nelore CEIP e as raças Nelore (não CEIP) e Girolando (Figura 3). 
Figura 3- Porcentagem de oócitos viáveis e não viáveis entre as diferentes raças.

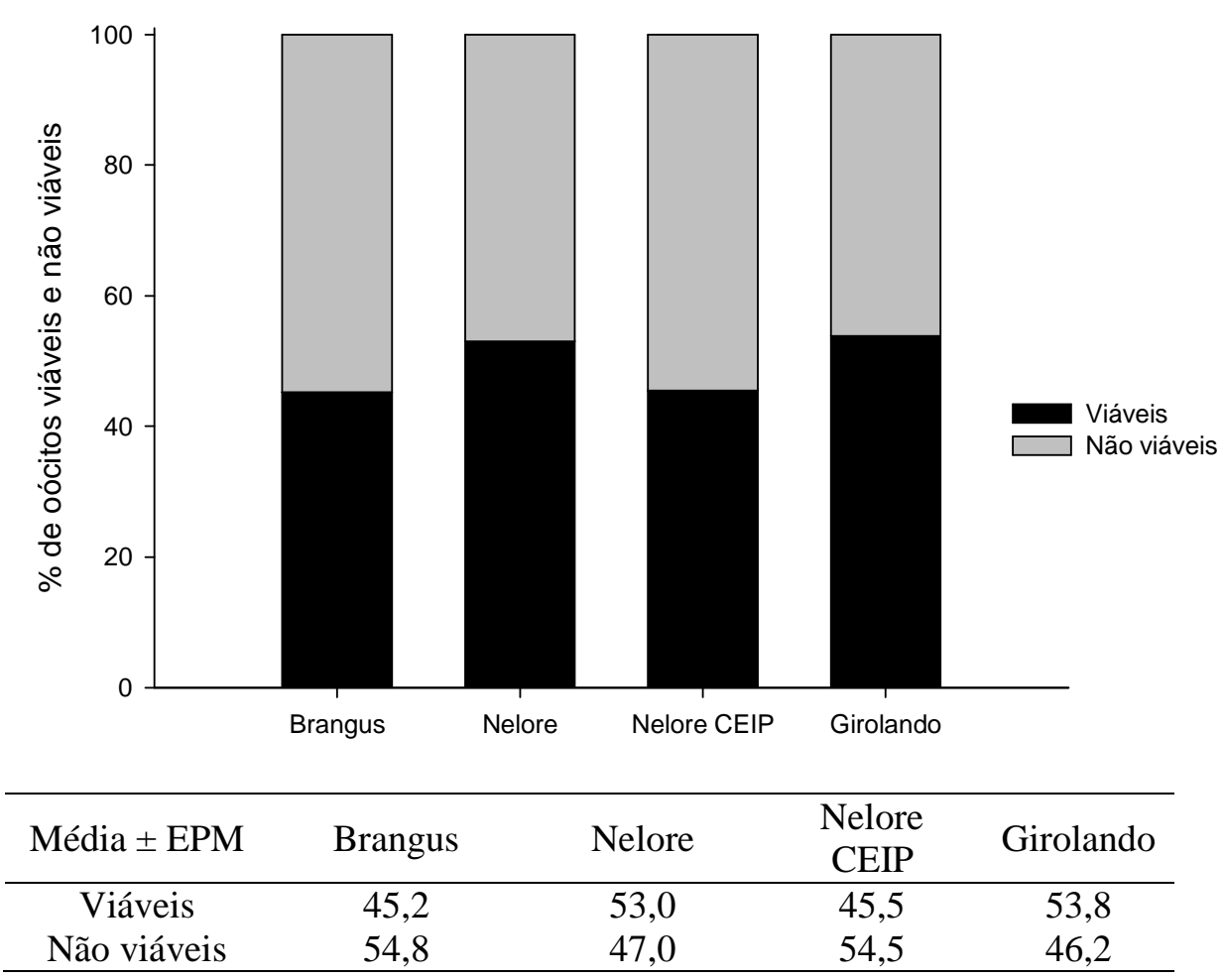

Com relação à produção de embriões a partir do número de oócitos viáveis recuperados por sessão de OPU, obteve-se na raça Nelore CEIP um número expressivo de oócitos viáveis (16.2) e embriões (4.1) produzidos, diferente estatisticamente $(P<0.0001)$ quando comparado às raças Brangus (2.0 embriões/OPU), Nelore (não CEIP) (2.2 embriões/OPU) e Girolando (2.3 embriões/OPU) (Figura 4). Porém quando se avaliou a taxa de produção de embriões com relação ao numero total de oócitos viáveis notou-se que não houve diferença estatística entre as raças (Nelore CEIP: 25.4\%, Brangus: 28.1\%, Nelore não CEIP: 28.4\% e Girolando: 25.8\%; $P>0,05$; Figura 5). 
Figura 4- Produção de embriões a partir do número de oócitos por sessão de OPU.

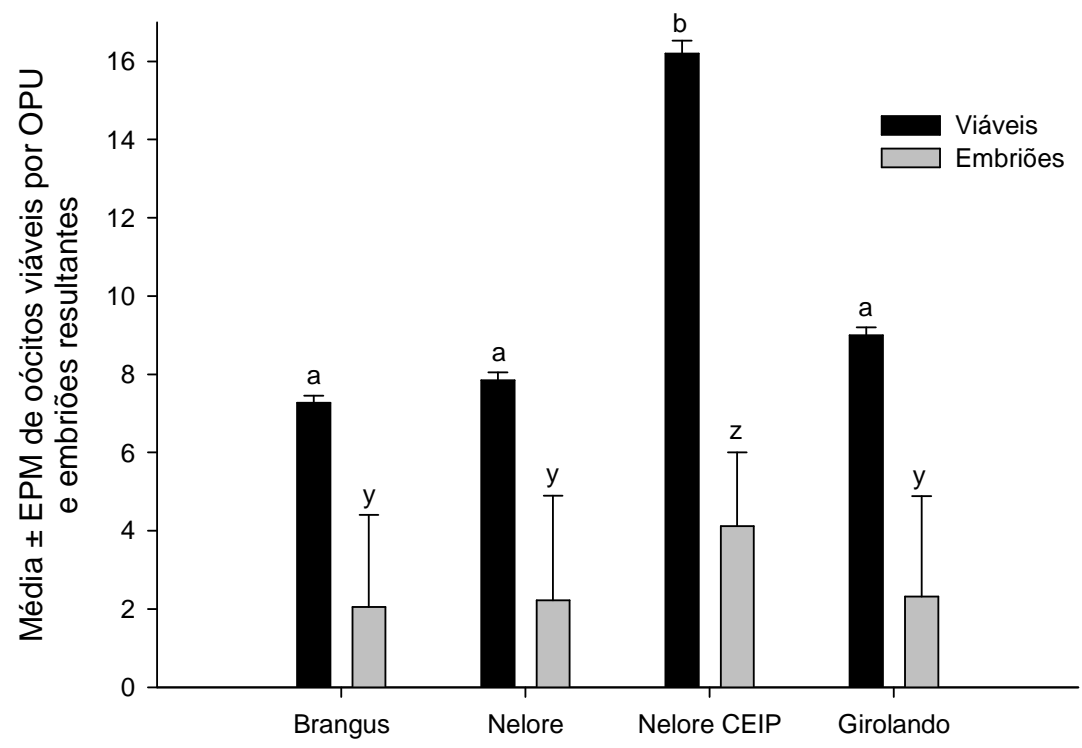

\begin{tabular}{cccccc}
\hline Média \pm EPM & Brangus & Nelore & $\begin{array}{c}\text { Nelore } \\
\text { CEIP }\end{array}$ & Girolando & $P$ \\
\hline Oócitos viáveis & $7,3 \pm 0,4^{\mathrm{a}}$ & $7,9 \pm 0,4^{\mathrm{a}}$ & $16,2 \pm 1,1^{\mathrm{b}}$ & $9,0 \pm 0,6^{\mathrm{a}}$ & 0,0001 \\
Embriões & $2,0 \pm 0,2^{\mathrm{y}}$ & $2,2 \pm 0,2^{\mathrm{y}}$ & $4,1 \pm 0,3^{\mathrm{z}}$ & $2,3 \pm 0,2^{\mathrm{y}}$ & 0,0001 \\
\hline
\end{tabular}

Letras minúsculas diferentes indicam diferenças estatísticas significativas.

Figura 5- Porcentagem de embriões produzidos de acordo com o número total de oócitos viáveis nas diferentes raças analisadas.

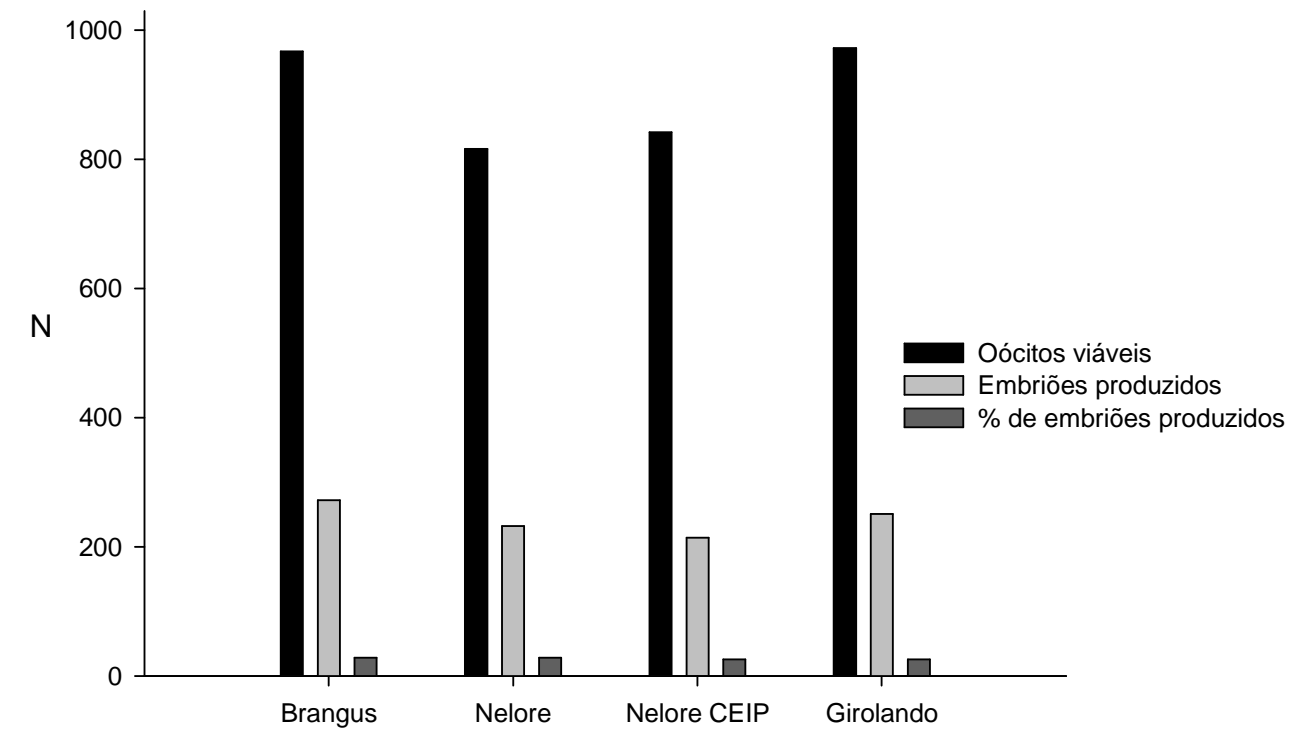

\begin{tabular}{ccccc}
\hline $\mathrm{N}$ & Brangus & Nelore & Nelore CEIP & Girolando \\
\hline Oócitos viáveis (A) & 967 & 816 & 842 & 972 \\
Embriões (B) & 272 & 232 & 214 & 251 \\
\hline$\%(\mathrm{~A} / \mathrm{B} ; p>0.05)$ & 28,1 & 28,4 & 25,4 & 25,8 \\
\hline
\end{tabular}


Dos embriões transferidos por sessão de OPU na raça Nelore CEIP $(4,1)$ difere estatisticamente $(P<0,0002)$ tais como as prenhezes obtidas $(1,2$ prenhezes $)(P<0,0115)$ com relação às outras raças, ou seja, nas raças Brangus produziu-se 1.8 embriões/OPU, Nelore (não CEIP) 2.3 embriões/OPU e Girolando 2.13 embriões/OPU obtendo-se 0.6 prenhes por sessão de OPU (Figura 6).

Figura 6- Média de embriões transferidos por OPU com relação às prenhezes.

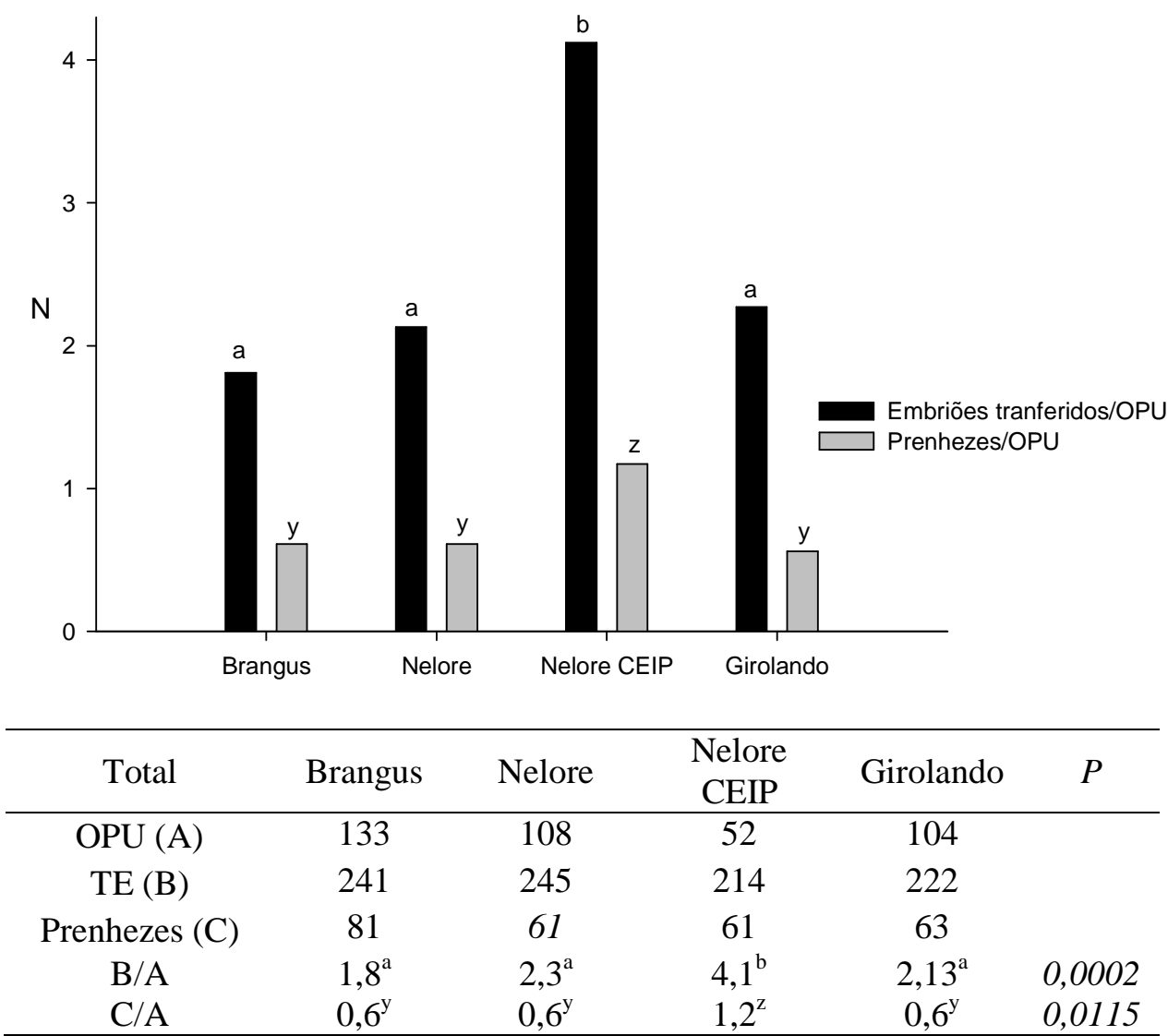

Letras minúsculas diferentes indicam diferenças estatísticas significativas. 
Figura 7- Taxas de prenhez comparada entre as diferentes raças.

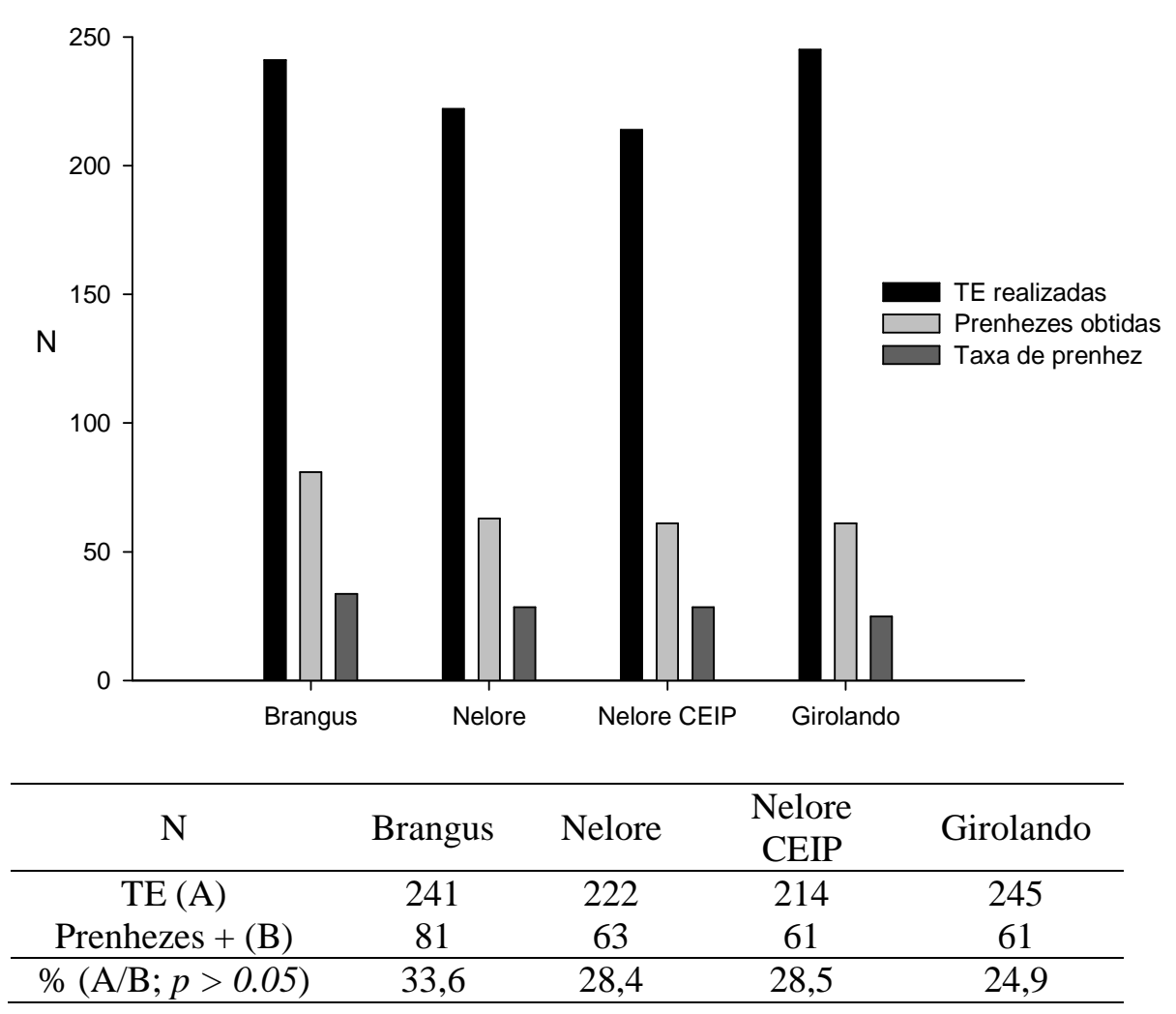

Na figura 7, pode-se observar que o número de embriões transferidos comparados às taxas de prenhezes obtidas aos 30 dias de gestação nas diferentes raças, não houve diferença estatística $(P>0,05)$. 


\section{DISCUSSÃO GERAL}

Com o presente trabalho se obteve dados ao longo de três anos com número relevante de aspirações e se comparou três raças importantes no território nacional. Tanto os animais como o laboratório de produção dos embriões estavam localizados na mesma propriedade. Todas as sessões de OPU foram realizadas pelo mesmo técnico, podendo-se afirmar que a variações técnicas foram diminutas. Poucos trabalhos foram realizados em larga escala de produção in vitro de embriões, podendo-se destacar como exemplo o de Pontes et al. (2009) que comparam resultados de prenhezes in vivo e in vitro em animais da raça Nelore, Pontes et al. (2010) forneceram dados sob a PIVE em larga escala de doadoras Bos taurus, Bos indicus e Bos indicus x Bos taurus. E, Pontes et al. (2011) descrevendo a produção em larga escala de embriões in vitro de fêmeas da raça Nelore.

Os dados aqui obtidos permitiram comparar a produção in vitro de embriões de animais de raças sintéticas (Bos tauros-indicus), com animais selecionados em programas de melhoramento genético para fertilidade (Nelore CEIP - Bos indicus), como sendo a maior raça pura em número de indivíduos no Brasil (Nelore - Bos indicus).

Durante a execução do trabalho foram recuperados 7335 oócitos, utilizando 172 doadoras em 397 sessões de aspiração (18.47 oócitos/OPU), dos quais resultaram em 3597 oócitos viáveis (49\%), obtendo-se 969 embriões (26.93\%), dos quais 922 foram transferidos em receptoras previamente selecionadas, resultando em 266 prenhezes (taxa de prenhez $=$ $28.85 \%)$.

Com relação à raça Nelore CEIP, recuperou-se uma média total de 35,6 oócitos por sessão de OPU (52 OPU/1850 oócitos), estes resultados são superiores aos encontrados por Pontes et al. (2009) cuja média total foi de 25,6 oócitos por OPU a de Pontes et al. (2011) com média total de 31,7 oócitos por sessão de OPU. Porém, nos animais da raça Nelore (não CEIP) foi obtido uma média inferior (14,8 oócitos/OPU; 104 OPU/1540 oócitos) aos resultados supracitados. A alta taxa de recuperação total de oócitos na raça Nelore (CEIPCertificado Especial de Identificação e Produção), se da ao fato de serem animais, oriundos de programas de melhoramento genético. De acordo com Parckert e Gallo (2011) estas avaliações são realizadas através de índices de fertilidade, precocidade sexual e produtividade, onde este certificado só é emitido para animais que comprovem serem melhoradores de suas safras. 
Vacas da raça Nelores normalmente têm uma maior quantidade de folículos de menor tamanho que as Bos tauros, sendo recuperados de 18 a 25 oócitos por sessão de OPU nos animais da raça Nelore. As fêmeas Bos indicus apresentam mais ondas foliculares ovarianas (três ondas) que as fêmeas Bos tauros (duas ondas), e também um maior número de folículos $>5 \mathrm{~mm}$ por onda. Devido a esta maior eficiência em se recuperar oócitos oriundos de folículos $<4 \mathrm{~mm}$ de diâmetro, uma maior quantidade de folículos menores são aspirados, consequentemente um maior número de oócitos são recuperados nos animais da raça Bos indicus que de doadoras Bos tauros (PONTES et al., 2009; PONTES et al., 2011; SILVASANTOS et al., 2011).

De acordo com Silva-Santos et al. (2011) o número de oócitos recuperados pela OPU em fêmeas Bos taurus indicus é duas a quatro vezes maior do que em fêmeas Bos taurus taurus. Porém, quando se comparou a população de folículos pré-antrais destas fêmeas, notou-se que o número destes folículos variou consideravelmente entre indivíduos de mesma categoria e entre as raças, não sendo este o provável fator que interfira na maior taxa de recuperação oocitária nos Bos indicus, mas talvez algum mecanismo envolvido no controle do desenvolvimento folicular pós-estágio pré-antral.

Silva-Santos et al. (2011) relata que não há diferença entre o número de folículos préantrais (primordiais, primários ou secundários) nos ovários de fetos ou novilhas da raça Nelore ou Bos taurus, sugerindo que o número total de folículos não seja a razão para tal diferença na produção de oócitos. Pontes et al. (2009) em prévios estudos, demonstrou que a taxa de recuperação por sessão de OPU/PIV na raça Holandês é de 4,1 oócitos na qual representa aproximadamente $16 \%$ do número de oócitos obtidos com a OPU nos animais da raça Nelore.

As fêmeas da raça Nelore têm uma grande variabilidade individual em relação ao número de folículos e oócitos, mas mesmo assim, a média de oócitos aspirados por sessão das raças de origem européia (1,9 a 9,9 oócitos/sessão de OPU) não superam as das raças zebuínas (18 a 25 oócitos/sessão de OPU) (PONTES et al., 2010). Devido a isso, têm sido identificados alguns fatores que podem interferir na produção de oócitos como idade (ERICKSON, et.al., 1976;RÜSSE, 1983), raça (CAHILL et al., 1979), níveis hormonais (PETERS, 1976), genética (ERICKSON, 1986), condição nutricional (SCARAMUZZI et al., 1993), estado reprodutivo (ERICKSON et al., 1976), estresse calórico e número de procedimentos de aspiração (PONTES et al., 2010). Porém Pontes et al. (2011) avaliou em seu experimento, animais com uma ou seis sessões de aspiração, e não houve diferença significativa na média produção de oócitos por doadora. $\mathrm{O}$ autor relata também que houve 
grande variação em algumas doadoras quanto ao número de oócitos recuperados por OPU, sendo a média constantemente alta em algumas doadoras (>30), baixa em outras $(<14)$ e considerável variação por procedimento em outras (de 5 a 40 oócitos) (PONTES et al., 2011).

As fêmeas da raça Nelore também parecem ter outras características especificas como onda de LH especifica e padrões únicos de metabolismo hormonal. Porem, ainda não se tem estabelecido a base fisiológica do número de folículos presentes nestes animais da raça Nelore. Outra hipótese controvérsia que tem sido sugerida devido à grande recuperação oocitária nos animais da raça Nelore é a renovação folicular ovariana, no entanto, este conceito deve ser melhor investigado antes de ser considerado (PONTES et al., 2011).

Nos animais da raça Girolando, foram encontrados neste estudo uma média total de 16,7 oócitos por OPU (108 OPU/1806 oócitos). Estes resultados foram inferiores aos obtidos por Pontes et al. (2010), que recuperou um média de 25,44 oócitos por sessão de OPU nos animais da raça Girolando ( $\mathrm{n}=81,12492$ oócitos em 492 sessões de OPU). Fato este que pode ser explicado pelo presente trabalho possuir a maior parte dos animais da raça Girolando com maior grau de sangue taurino (5/8 Holandês x $3 / 8$ Gir), diferentemente dos animais do trabalho de Pontes et al. (2010) os quais eram 1/2 Gir x 1/2 Holandês e 1/4 Holandês x 3/4 Gir.

$\mathrm{Na}$ raça Brangus, aqui apresentada, foram recuperados uma média total de 16,1 oócitos por sessão de OPU (133 OPU/2139 oócitos). Porém, na literatura não foram encontrados trabalhos de PIV em animais oriundos do cruzamento de 5/8 Bos taurus x 3/8 Bos indicus de raças de corte.

Em comparação com o número de oócitos viáveis por sessão de OPU entre as raças deste experimento, percebeu-se que nos animais Nelore CEIP foram recuperados um maior número de oócitos viáveis (16.2), quando comparado aos oócitos viáveis nas raças Brangus (7.3), Nelore (não CEIP) (7.9) e Girolando (9.0). Resultados semelhantes com a raça Nelore (CEIP) foram encontrados por Stroud e Callesen (2012), em um levantamento na PIVE no mundo, onde o autor encontrou uma média de 16 oócitos viáveis por OPU, porém estes resultados são superiores comparados aos encontrados neste presente trabalho com as raças Brangus, Girolando e Nelore (não CEIP). Estes resultados foram considerados inferiores, comparado aos achados de Pontes et al. (2009), que recuperou 23 oócitos viáveis por OPU em fêmeas Nelore, e também inferiores com os de Pontes et al. (2011), que obteve em fêmeas Nelore uma média de 24 oócitos viáveis por OPU. Na raça Girolando, Pontes et al. descreve resultados superiores aos encontrados neste trabalho (média de 20 oócitos viáveis por sessão de OPU). 
Comparando a porcentagem de oócitos viáveis por sessão de OPU entre as raças, notou-se que as raças Nelore (CEIP) e Brangus, percebeu-se as mesmas porcentagens (45.5\% e $45.2 \%$ ) respectivamente, porém elas apresentaram médias inferiores relacionadas as obtidas nas raças Nelore (não CEIP) e Girolando (53\% e 53.8\%) respectivamente. Estes resultados são inferiores comparados e resultados obtido por Pontes et al. (2011), onde foi descrito que fêmeas Nelore apresentaram uma taxa de $75.5 \%$ de oócitos viáveis. Pontes et al. (2009) obteve em seu experimento uma taxa de $89 \%$ de oócitos viáveis em animais da raça Nelore.

Com relação à produção de embriões por sessão de OPU, obteve-se com este experimento na raça Nelore (CEIP) um número de 4,1 embriões produzidos por OPU, este resultado se mostrou superior quando comparado aos resultados obtidos nas raças Brangus (2.0 embriões/OPU), Nelore (não CEIP) (2.2 embriões/OPU) e Girolando (2.3 embriões/OPU). Resultados encontrados em fêmeas Nelore por Pontes et al. (2011)se mostraram superiores, obtendo uma média de 8 embriões por sessão de OPU, o autor ainda relata em seu trabalho que doadoras com alta produção de oócitos produziram significativamente mais embriões que aqueles de baixa produção de oócitos (PONTES et al., 2011), estando de acordo com os resultados obtidos no presente trabalho na raça Nelore (CEIP). Em outro trabalho em animais Nelore, Pontes et al. (2009) obteve uma média de 9 embriões por sessão de aspiração. Porém em fêmeas Girolando, Pontes et al. (2010) obteve uma média de 4.6 embriões por OPU, demonstrando assim uma média de produção de embriões menor em animais Girolando (Bos indicus x Bos tauros) comparado a raça Nelore (Bos indicus) . A avaliação da taxa de produção de embriões em relação ao número total de oócitos viáveis não apresentou diferença estatística entre as raças (Nelore CEIP: 25.4\%, Brangus: 28.1\%, Nelore (não CEIP): 28.4\% e Girolando: 25.8\%). Pontes et al. 2010, descreve resultados inferiores obtidos em vacas da raça Girolando (23\% de embriões). Resultados superiores ao apresentado no presente estudo, foram encontrados por Pontes et al. (2011) e Stroud e Callesen (2012) onde se obteve taxas de $31.4 \%$ e $32 \%$ respectivamente, entretanto os resultados encontrados por Pontes et al. (2009) são ainda maiores, onde o autor descreve uma taxa de $41 \%$ de produção de embriões de acordo com o total de oócitos viáveis.

O número de prenhezes por sessão de OPU obtido no presente experimento foi de 0,6 nas raças Brangus, Nelore (não CEIP) e Girolando, entretanto na raça Nelore (CEIP) se obteve um resultado superior estatisticamente de 1,2 prenhezes por sessão de OPU, diferentes dos resultados encontrados na raça Nelore por Pontes et al. (2009) (3,5 prenhezes/OPU) e Pontes et al. (2011) (3 prenhezes/OPU). Pontes et al. (2010) em animais da raça Girolando obteve um resultado semelhante (1,4 prenhes/OPU) aos descritos neste trabalho na raça 
Nelore (CEIP), porém foram superiores comparados aos obtidos com a raça Girolando neste experimento. Quanto à taxa de prenhes, neste experimento foram obtidas nas raças Brangus $33.6 \%$ de prenhes, Nelore (não CEIP) $28.4 \%$, Girolando $24.9 \%$ e Nelore (CEIP) $28.5 \%$ de prenhes, não havendo diferença estatística significativa entre as raças. Outros trabalhos na raça Nelore apresentam resultado pouco superiores de 37\% (PONTES et al., 2009) e 36\% (PONTES et al., 2011), e de 37\% de prenhes na raça Girolando (PONTES et al., 2010).

A taxa de prenhes esta diretamente ligada com a qualidade do embrião, à mão de obra técnica e principalmente a qualidade e disponibilidade das receptoras. Alguns trabalhos descrevem baixas taxas de prenhes relacionado a qualidade de receptoras (PONTES et al., 2009; PONTES et al., 2011). Vale ressaltar que ainda são necessários mais estudos relacionados à produção in vitro de embriões nessas raças, no intuito de melhorar sua eficiência para escala comercial. 


\section{CONCLUSÕES}

O presente trabalho forneceu dados inéditos de PIVE nas raças sintéticas Brangus e Girolando (Bos tauros x Bos indicus), e mostraram que esses animais podem ser utilizados em programas de PIVE em larga escala.

Concluímos através do comparativo entre as raças, que a quantidade total de oócitos não variou de acordo com as raças Brangus, Girolando e Nelore, no entanto podemos notar uma grande variação individual de animais da mesma raça, selecionados por programas de melhoramento genético (Nelore CEIP) ou não selecionadas (Nelore não CEIP), onde se obteve nas fêmeas da raça Nelore (CEIP, selecionadas) uma maior produção total de oócitos, oócitos viáveis e embriões por sessão de aspiração.

Este trabalho também demonstrou que animais que passaram por um processo de seleção para produção e fertilidade (Nelore CEIP), através de programas de melhoramento genético, apresentaram uma maior taxa de recuperação de oócitos e consequentemente maior produção in vitro de embriões.

Sugerimos com os resultados deste trabalho, que os animais sejam submetidos a programas de melhoramento genético que visam uma seleção de fertilidade, para melhoria da PIVE. Sugerimos também que sejam realizados trabalhos com animais Nelore (CEIP), com relação a sua dinâmica folicular, hormonal e contagem populacional de folículos ovarianos. 


\section{REFERÊNCIAS}

AMER, P. R.; EMMANS, G. C.; SIMM, G. Breeding objectives for beef cattle in Ireland. Livestock Production Science, v. 67, n. 2, p. 223-239, 2001.

AX, R.L.; DALLY, M.R.; DIDION, B.A.; LENZ, R.W.; LOVE, C.C.; VARNER, D.D.; HAFEZ, B.; BELLIN, M.E. Inseminação artificial. In: HAFEZ, E.S.E.; HAFEZ, B.

Reprodução animal. 7. ed. São Paulo: Manole, 2004. p. 381-2

BAK, A.; GREVE, T.; SCHMIDT, M. Effect of superovulation on reproduction.

Theriogenology, Stoneham, v. 31, p. 169, 1989. (Abstract).

BANKS, W. J. Histologia veterinária aplicada. 2. ed. São Paulo: Manole, 1992. p. 565-572

BASSO, A. C.; SCHNEIDER, C. L.; PONTES, J. H. F. Novas alternativas para aplicação em larga escala de embriões produzidos in vitro. In: SIMPÓSIO INTERNACIONAL DE REPRODUÇÃO ANIMAL APLICADA. 4º Londrina. 2010. p. 205-9

BAVISTER B. D. A consistently successful procedure for in vitro fertilization of golden hamster eggs. GAMETE RES, v. 23, p. 139-158, 1989.

BECKER, F.; KANITZ, W.; NURNBERG, G.; KURTH, J.; SPITSCHAK, M. Comparison of repeated transvaginal ovum pick-up in heifer by ultrasonographic and endoscopic instruments. Theriogenology. v. 46, p. 999-1007, 1996.

BETTERIDGE, K. J.; SMITH, C.; STUBBINGS, R. B.; XU, K. P; KING, W. A. Potential genetic improvement of cattle by fertilization of fetal oocytes in vitro. Journal

Reproduction Fertility. v. 38, p. 87-98, 1989.

BLASCHI, W.; ANDRADE, E. R.; NONATO JR. I.; PONTES, J. H. F.; ERENCO JR, J.C.; UVO, S.; SENEDA, M. M. Pluset prior follicle aspiration: Impact onin vitro embryo production in Bos indicus cows. Acta Scientiae Veterinariae, v. 32, p. 186, 2004. (Abstract)

BOLS, P. E. J.; SOOM, A.V.; VANROOSE, G.; KRUIF, A. Transvaginal oocyte pick-up in infertile Belgian Blue donors cows: Preliminary results. Theriogenology, v. 45, p. 359, 1996a. 
BOLS, P. E. J.; VAN SON, A.; YSEBAERT, M. T.; VANDENHEEDE, J. M. M, KRUIF, A. Effects of aspiration vacum and needle diameter on cumulus oocyte complex morphology and developmental capacity of bovine oocytes. Theriogenology, v.45, p.1001-14, 1996b.

BOLS, P. E. J.; YSEBAERT, M. T.; VAN SON, A.; KRUIF, A. Effects of needle tip bevel and aspiration procedure on the morphology and developmental capacity bovine compact cumulus oocyte complexes. Theriogenology, v. 47, p. 1221-1236, 1997.

BRACKETT, B. G.; BOUSQUET, D.; BOICE, M. L.; VICK DONA, W. J.; EVANS, J. F.; DRESSEL, .M. A. Normal development following in vitro fertilization in the cow. Biology of Reproduction, v. 101, p. 147-58, 1982.

BRASIL. Ministério da Agricultura. Bovinos e bubalinos. [200-]. Disponível em: <http://www.agricultura.gov.br/animal/especies/bovinos-e-bubalinos >. Acesso em: 12 mar. 2013.

BRASIL. Ministério da Agricultura. Brasil projeções do agronegócio 2011/2012 a 2021/2022. 2012. Disponível em:

<http://www.agricultura.gov.br/arq_editor/file/Ministerio/gestao/projecao/Projecoes\%20do\% 20Agronegocio\%20Brasil\%202011-20012\%20a\%2020212022\%20\%282\%29\%281\%29.pdf>. Acesso em: 12 mar. 2013.

BRAW-TAL, R.; YOSSEFI, S. Studies in vivo and in vitro on the initiation of follicle growth in the bovine ovary. Journal Reproduction Fertility, v. 109, p. 165-171, 1997.

BUNGARTZ, L.; HAHN, L. A.; NEIEMANN, H. Collection of oocytes from cattle via follicular aspiration aided by ultrasound with or without gonadotropin pretreatment and in different reproductive stages. Theriogenology, v. 43, p. 667-75, 1995.

CAHILL, L. P.; MARIANA, J. C.; MAULEON, J. Total Follicular Populations in Ewes of High and Low Ovulation Rates. Journal Reproduction Fertility, v. 55, p. 27-36, 1979.

CORMACK, D. H. O sistema reprodutor feminino. In: CORMACK, D. H. Ham Histologia, 9. ed, Rio de Janeiro: Guanabara Koogan, , 1991. p. 485-508

DRIANCOURT, M. A. Follicular dynamics in sheep and cattle. Theriogenology, v. 33, p. 55-73, 1991. 
ERICKSON, B. H.; REYNOLDS, R. A.; MURPHREE, R. L. Ovarian characteristics and reproductive performance of the aged cow. Biology Reproduction, v. 15, p. 555-560, 1976.

ERICKSON, G. F. An analysis of follicle development and ovum maturation. Seminars in reproductive endocrinology, v. 4, p. 233-54, 1986.

FIGUEIREDO, R. A.; BARROS C. M.; PINHEIRO O. L.; SOLER, J. M. P. Ovarian follicular dynamics in Nellore breed (Bos indicus) cattle. Theriogenology, v. 47, p. 1489-505, 1997.

FORTUNE, J. E. Ovarian follicular growth and development in mamals. Biology

Reproduction, v. 50, p. 225-32, 1994.

GEORGE, L. L.; ALVES, C. E. R.; CASTRO, R. R. L. Histologia Comparada. 2. ed. São Paul: Rocca, 1998. p. 237-40

GINTHER, O. J.; KNOPF, L.; KASTELIC, J. P. Temporal associations among ovarian events in cattle during oestrous cycles with two and three follicular waves. Journal of Reproduction and Fertility, v. 87, p. 223-30, 1989.

GONÇALVES, P. B. D.; OLIVEIRA, M. A. L.; MEZZALIRA, A.; MONTAGNER, M. M.; VISINTIN, J. A.; COSTA, L. F. S.; Produção in vitro de embriões. In: GONÇALVES, P. B. D.; FIGUEIREDO, J. R.; FREITAS, V. J. F. Biotécnicas aplicadas a reprodução animal. 2. ed. São Paulo: Roca, 2008. p. 261-91

GONÇALVES, P. B. D.; VISINTIN, J. A.; OLIVEIRA, M. A. L.; MONTAGNER, M. M.; COSTA, L .F. S. Produção in vitro de embriões. In: GONÇALVES, P. B. D.; FIGUEIREDO, J. R.; FREITAS, V. J. F. Biotécnicas aplicadas a reprodução animal. 1. ed. São Paulo: Varela, 2002. p. 195-226

GORDON, I. Prenatal development of the bovine ovary. In: GORDON, I. Laboratory production of cattle embryos. Cambridge: CAB International: Raven Press, 1994. p. 4349

HAFEZ, E. S. E. Anatomy of Female Reproduction. In: HAFEZ, E. S. E. Reproduction in Farm Animals. 6. ed. Pennsylvania: Williams \& Wilkins, 1996. p. 20-58,

HANEKAMP, W. J. A. Transfer of beef embryos in dairy cows: influence of recipient and embryo quality on pregnancy rate and calving performance. Reproduction Domestical Animal. v. 34, p. 459-63, 1999. 
HASHIMOTO, S.; TAKAKURA, R.; KISHI, M.; SUDO, T.; MINAMI, N.; YAMADA, M. Ultrasound-guided follicle aspiration: effect o the frequency of a linear transvaginal probe on the collection of bovine oocytes. Theriogenology, v. 52, p. 131-8, 1999.

HASLER, J. F.; HENDERSON, W. B.; HURTGEN, P. J.;JIN, Z. Q.;MCCAULEY, A. D.; MOWER, S. A.;NEELY, B.;SHUEY, L. S.;STOKES, J. E.;TRIMMER, S. A. Production, freezing and transfer of bovine IVF embryos and subsequent calving results. Theriogenology, v. 43, p. 141-52, 1995.

HIRSHFIELD, A. N. Development of follicles in the mammalian ovary. International Rew. Cytology. v. 124, p. 43-101, 1991.

HULSHOF, S. C. J.; FIGUEIREDO, J. R.; BEKERS, J. F.; BEVERS, M. M.; VAN DER DONK, J. A. Effects of fetal bovine serum, FSH and 17ß-estradiol on the culture of bovine preantral follicles. Theriogenology, v. 44, p. 217-26, 1995.

HULSHOF, S. C. J.; FIGUEIREDO, J. R.; BEKERS, J. F.; BEVERS, M. M.; VAN DEN HURK, R. Isolation and Characterization of preantral follicles from fetal bovine ovaries. The Veterinary Quartely, v. 2, n. 16, p. 78-80, 1994.

INGRAN, D. L. Atresia. In: ZUCKERMAN, S. The ovary. Academic Press, New York, p. 247-273, 1962.

IRELAND, J. J. Control of Follicular Growth and Development. Journal Reproduction Fertility. v.34, p. 39-54, 1987.

JAINUDEEN, M. R.; WAHID, H.; HAFEZ, E. S. E. Indução da ovulação, produção e transferência de embriões. In: HAFEZ, E. S. E.; HAFEZ, B. Reprodução animal. 7. ed. São Paulo: Manole, 2004. p. 409-34

JEWGENOW, K.; PITRA, C. Hormone-controled culture of secondary follicles of domestic cats. Theriogenology, v. 39, p. 527-535, 1993.

KRUIP, T. A. M.; BONI, R.; WURTH, Y. A.; ROELOFSEN, M. W. M.; PIETERSE, M. C. Potential use of ovum pick-up for embryo production and breeding in cattle.

Theriogenology, v. 42, p. 675-84, 1994. 
LIU, J.; VAN DER ELST, J.; VAN DEN BROECK, R.; DHONT, M. Live offspring by in vitro oocytes from cryopreserved primordial mouse follicles after sequential in vivo transplantation and in vitro maturation. Biology Reproduction, v. 64, p. 171-8, 2001.

LÔBO, R. B.; BEZERRA, L. A. F.; OLIVEIRA, H. N. Avaliação genética de animais jovens, touros e matrizes. Ribeirão Preto: GEMAC — Departamento de Genética - FMRP USP, 2000. 90 p.

LUCCI, C. M., AMORIM, C. A., RODRIGUES, A. P. R., FIGUEIREDO, J. R, BÁO, S. N., SILVA, J. R. V.; GONÇALVES, P. B. D. Study of preantral follicle population in situ and after mechanical isolation from caprine ovaries at different reproductive stages. Animal Reproduction Science, v. 56, p. 223-36, 1999.

LUSSIER, J. G.; MATTON, P.; DUFOUR, J. J. Growth rates of follicles in the ovary of the cow. J. Reprod. Fert., v. 81, p. 301-307, 1987.

MOORE, K. L.; PERSAUD, T. V. N. Início do desenvolvimento humano. In: MOORE, K.L. e PERSAUD, T.V.N. Embriologia Clínica. 5. ed. Rio de Janeiro: Guanabara Koogan, 1994. p. $13-38$

PARCKERT, L.; GALLO, S. B. Uma abordagem sobre os principais programas de melhoramento genético do Brasil. Caderno de pós-graduação da FAZU. v. 2, 2011. (Resumo)

PARRISH, J. J.; SUSKO-PARRISH, J. L.; LEIBFRIEDGE-RUTHEDGE, M. L.; CRITSER, E. S.; EYESTONE, W. H.; FIRST, N. L. Bovine in vitro fertilization with frozen thawed semen. Theriogenology, v. 25, p.591-600, 1986.

PEIXOTO, M. G. C. D.; BERGMANN, J. A. G.; FONSECA, C. G.; PENNA, V. M.; PEREIRA, C. S. Effects of environmental factors on multiple ovulation of zebu donors. Arquivo Brasileiro de Medicina Veterinária e Zootecnia, v. 58, p. 567-74, 2006.

PEIXOTO, M. G. C. D.; BERGMANN, J. A. G.; SUYAMA, E.; CARVALHO, M. R. S.; PENNA, V. M. Logistic regression analysis of pregnancy rate following transfer of Bos indicus embryos into Bos indicus x Bos taurus heifers. Theriogenology, v. 67, p. 287-92, 2007.

PETERS, H. The development and maturation of the ovary. Ann. Biol. Anim. Bioch. Biophys, v. 16, n. 3, p. 271-8, 1976. 
PIETERSE, M. C.; KAPPEN, R. A.; KRUIP, .A. M.; TAVERNE, M. A. M. Aspiration of bovine oocytes during transvaginal ultrasound scanning of the ovaries. Theriogenology, $v$. 30, p. 751-62, 1988.

PIETERSE, M. C.; VOS, P. L. A. M.; KRUIP, A. M.; WURTH, Y. A.; VAN BENEDEN, .H.; WILLEMSE, A. H.; TAVERNE, M. A. M. Transvaginal ultrasound guided follicular aspiration of bovine oocytes. Theriogenology, v. 35, p. 19-24, 1991.

PONTES, J. H. F. K.; SILVA, K. C. F.; BASSO, A. C.; RIGO, A. G.; FERREIRA, C. R.; SANTOS, G. M. G.; SANCHES, B. V.; PORCIONATO, J. P. F; VIEIRA, P. H. S.; FAIFER, F. S.; STERZA, F. A. M.; SCHENK, J. L.; SENEDA, M. M. Large-scale in vitro embryo production and pregnancy rates from Bos taurus, Bos indicus, and indicus-taurus dairy cows using sexed sperm.Theriogenology, v. 74, p. 1349-55, 2010.

PONTES, J. H. F.; MELO STERZA, F. A.; BASSO, A. C.; FERREIRA, C. R.; SANCHES, B. V.; RUBIN, K. C. P.; SENEDA, M. M. Ovum pick up, in vitro embryo production, and pregnancy rates from a large-scale commercial program using Nelore cattle (Bos indicus) donors. Theriogenology, v. 75, p. 1640-46, 2011.

PONTES, J. H. F.; NONATO-JUNIOR, I.; SANCHES, B. V.; ERENO-JUNIOR, J. C.; UVO, S.; BARREIROS, T. R. R.; OLIVEIRA, J. A.; HASLER, J. F.; SENEDA, M. M. Comparison of embryo yield and pregnancy rate between in vivo and in vitro methods in the same Nelore (Bos indicus) donor cows. Theriogenology, v. 71, p. 690-97, 2009.

REICHENBACH, H. D.; MORAES, J. C. F.; NEVES, J. P. Tecnologia do sêmen e inseminação artificial em bovinos. In: GONÇALVES, P. B. D.; FIGUEIREDO, J. R.; FREITAS, V. J. F. Biotécnicas aplicadas à reprodução animal. 2. ed. São Paulo: Roca, 2008. p. $57-58$

RUSSE, I. Oogenesis in Cattle and Sheep. Bibl. Anat., v. 24, p. 77-92, 1983.

SAUMANDE, J. La folliculogenèse chez les ruminants, Rec. Vét., v. 167, p. 205-218, 1991. SCARAMUZZI, R. J., ADAMS, N. R., BAIRD, D. T., CAMPBELL, B. K., DOWNING, J. A., FINDLAY, J. K., HENDERSON, K. M., MARTIN, G. B., MCNATTY, K. P., MCNEILLY, A. S.; TSONIS, C. G. A model for follicle selection and the determination of ovulation rate in the ewe. Reprod. Fertil. Dev., v. 5, p. 459-78, 1993. 
SENEDA, M. M.; ESPER, C. R.; GARCIA, J. M.; OLIVEIRA, J. A.; VANTINI, R. Relationship between follicle size and ultrasound-guided transvaginal recovery. Animal Reproduction Science, V. 67, p. 37-43, 2001.

SENEDA, M. M.; ESPER, C. R.; GARCIA, J. M.; ANDRADE, E. R. Aspectos técnicos e biológicos da obtenção de oócitos bovinos: Revisão de literatura. Semina, v. 23, n. 1, p. 101$10,2002$.

SENEDA, M. M.; ESPER, C. R.; GARCIA, J. M.; ANDRADE, E. R.; BINELLI, M.; OLIVEIRA J. A.; NASCIMENTO, A. B. Efficacy of linear and convex transducers for ultrasound-guided transvaginal follicle aspiration. Theriogenology, v. 59, p. 1435-40, 2003.

SILVA-SANTOS, K. C.; SANTOS, G. M. G.; SILOTO, L. S.; HERTEL, M. F.; ANDRADE, E. R.; RUBIN, M. I. B.; STURION, L.; MELO-STERZA, F. A.; SENEDA, M. M. Estimate of the population of preantral follicles in the ovaries of Bos taurus indicus and Bos taurus taurus cattle. Theriogenology, v. 76, p. 1051-7, 2011.

STROUD, B.; CALLESEN, H. Declaração a IETS sobre as estatísticas mundiais de transferência de embriões para 2010.ANAIS DA XXVI REUNIÃO ANUAL DA SOCIEDADE BRASILEIRA DE TECNOLOGIA DE EMBRIÕES, 26. Foz do Iguaçú, 2012. p. $111-7$

VAN DEN HURK, R.; BEVERS, M. M.; BECKER, J. F. In vivo and in vitro development of preantral follicles. Theriogenology, v. 47, p. 73-82, 1997.

VAN WAGTENDONK-DE LEEUW, A. M. Ovum Pick Up and In vitro Production in the bovine after use in several generations: 2005 status. Theriogenology, v. 65, p. 914-25, 2006.

WASSARMAN, P. M. The mammalian ovum. In: KNOBIL, E. \& NEILL, J. The physiology of reproduction. New York, Raven Press, 1988. p. 69-101

WATANABE, Y. F.; ACCORSI, M. F.; WATANABE, M. R.; DAYAN, A.; MEIRELLES, F. V. Aspectos comercial de embriões bovinos produzidos in vitro. In: GONÇALVES, P. B. D.; FIGUEIREDO, J. R.; FREITAS, V. J. F. Biotécnicas aplicadas a reprodução animal. 2. ed. São Paulo: Roca, 2008. p. 293-301

WILLET, E. L.; BLACK, W. G., CASIDA, L. E., STONE, W. H., BUCKNER, P. J. Successful transplantations of fertilized bovine ovum. Science, v. 113, p. 247, 1951. 